\title{
Crystallizing Vanadium Pentoxide Nanostructures in the Solid-State Using Modified Block Copolymer and Chitosan Complexes
}

\author{
C. Diaz, ${ }^{1}$ G. Barrera, ${ }^{1}$ M. Segovia, ${ }^{1}$ M. L. Valenzuela, ${ }^{2}$ M. Osiak, ${ }^{3}$ and C. O'Dwyer ${ }^{3,4}$ \\ ${ }^{1}$ Departamento de Química, Facultad de Química, Universidad de Chile, La Palmeras 3425, Casilla Postal 653, Nuñoa, \\ 780-0026 Santiago de Chile, Chile \\ ${ }^{2}$ Universidad Autónoma de Chile, Instituto de Ciencias Aplicadas, El Llano Subercaseaux 2801, San Miguel, 780-0026 Santiago, Chile \\ ${ }^{3}$ Department of Chemistry, University College Cork, Cork, Ireland \\ ${ }^{4}$ Micro \& Nanoelectronics Centre, Tyndall National Institute, Lee Maltings, Cork, Ireland
}

Correspondence should be addressed to C. Diaz; cdiaz@uchile.cl and C. O’Dwyer; c.odwyer@ucc.ie

Received 7 December 2014; Revised 12 April 2015; Accepted 15 April 2015

Academic Editor: Subrata Kundu

Copyright $\odot 2015$ C. Diaz et al. This is an open access article distributed under the Creative Commons Attribution License, which permits unrestricted use, distribution, and reproduction in any medium, provided the original work is properly cited.

A systematic study of the synthesis of $\mathrm{V}_{2} \mathrm{O}_{5}$ nanostructured materials using macromolecular PS-co-4-PVP. $\left(\mathrm{VCl}_{3}\right)_{y}$ and chitosan $\cdot\left(\mathrm{VCl}_{3}\right)_{y}$ complexes is presented. It is demonstrated that various coordination degrees of the metal into the polymeric chain specifically influence the product formation after pyrolysis. PS-co-4-PVP. $\left(\mathrm{VCl}_{3}\right)_{y}$ and chitosan $\cdot\left(\mathrm{VCl}_{3}\right)_{y}$ complexes were prepared by simple coordination reaction of $\mathrm{VCl}_{3}$ with the respective polymer in molar ratios $1: 1,1: 5$, and 1:10 metal/polymer and characterized by elemental analysis, IR spectroscopy, and TGA/DSC analysis. Solid-state thermolysis of these precursors at several temperatures under air results in nanostructured $\mathrm{V}_{2} \mathrm{O}_{5}$ using all precursors. The size and shape of the nanostructured $\mathrm{V}_{2} \mathrm{O}_{5}$ depend on the nature of the polymer. For the chitosan $\left(\mathrm{VCl}_{3}\right)_{y}$ precursors sub-10 nm nanocrystals are formed. The calcination process, involved in the preparation method, produces $\mathrm{V}_{2} \mathrm{O}_{5}$ with photoluminescence in the visible light region, suggesting the possible application in oxygen sensing devices.

\section{Introduction}

Vanadium oxides with a unique characteristic structure comprise a particularly interesting group of inorganic $3 \mathrm{~d}-$ transition metal oxide compounds due to their diverse electronic, optoelectronic, electrochromic, and magnetic properties $[1,2]$, which makes them potential candidates for important technological applications. $\mathrm{V}_{2} \mathrm{O}_{5}$ has useful properties with potential for the development of electrochromic devices, information displays, and color memory devices [3, 4]. The ability to incorporate large amount of lithium ions coupled with its peculiar optical properties ranks vanadium oxides among the most studied materials for electrochemical applications in general and in particular for applications in high-energy density solid-state batteries and information displays [5-8]. For all these applications a solid-state method to prepare these $\mathrm{V}_{2} \mathrm{O}_{5}$ nanoparticles would prove very useful in cases where sensitivity to water or solvents needs to be avoided.

Although several solution-based methods to prepare $\mathrm{V}_{2} \mathrm{O}_{5}$ nanoparticles have been reported [9-18], their isolation to form a solid product causes large scale agglomeration resulting in near to a bulk-like phase. Solid-state routes to nanostructured $\mathrm{V}_{2} \mathrm{O}_{5}$ with controlled stoichiometry remain a challenge. The closest solid-state method to prepare nanostructured $\mathrm{V}_{2} \mathrm{O}_{5}$ is the thermal treatment of $\mathrm{NH}_{4} \mathrm{VO}_{3}$ [19] and from thermolysis of the precursor $\mathrm{NH}_{4} \mathrm{~V}_{3}(\mathrm{OH})_{6}\left(\mathrm{SO}_{4}\right)_{2}$ [20]. Previously we have reported the formation of $\mathrm{VO}_{x} / \mathrm{VO}\left(\mathrm{PO}_{4}\right)_{n}$ mixture phases from thermal treatment of organometallic derivatives of phosphazene [21]. The preparation of mixtures phases could be avoided using an organic polymer as PS- $\mathrm{co}$ 4-PVP and chitosan [22] (Scheme 1) as solid-state template.

Chitosan is chosen as a low-cost commercial product and because of its effective coordinative properties to metal ions. 
TABLE 1: Experimental details of the reactions for the formation of the precursors.

\begin{tabular}{|c|c|c|c|c|}
\hline Precursor & Ratio M/polymer & Mass of polymer (g) & Mass of metallic salt $(\mathrm{g})$ & Color of the product \\
\hline \multirow{3}{*}{ PSP-co-4-PVP. $\left(\mathrm{VCl}_{3}\right)_{y}$} & (1) $1: 1$ & 0.3316 & 0.4990 & Gray-green \\
\hline & (2) $1: 5$ & 1.615 & 0.5181 & Gray-green \\
\hline & (3) $1: 10$ & 1.112 & 0.1709 & Black \\
\hline \multirow{3}{*}{ Chitosan $\cdot\left(\mathrm{VCl}_{3}\right)_{y}$} & (4) $1: 1$ & 0.5577 & 0.5016 & Black \\
\hline & (5) $1: 5$ & 2.791 & 0.1712 & Red-dark \\
\hline & (6) $1: 10$ & 1.856 & 0.058 & Green-dark \\
\hline
\end{tabular}

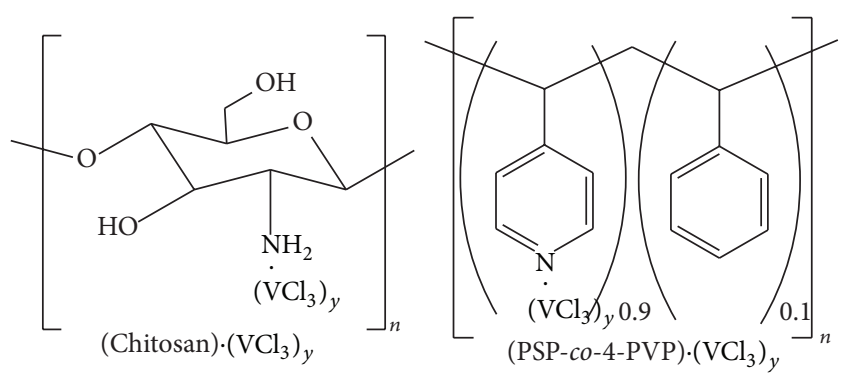

SCHEME 1: Representative formulas of chitosan and poly(styreneco-4-vinylpyridine) and possible coordination sites of $\mathrm{VCl}_{3}$ to the polymeric chain.

Chitosan [23-25] is a polysaccharide obtained by deacetylation of natural chitin, which is one of the important natural polymers constituting the shells of crustaceans and the cell wall of many fungi. Due to $\mathrm{NH}_{2}$ groups and $\mathrm{OH}$ moieties present in the polysaccharide chains, it can bind metal ions in solution forming macromolecular metal complexes [2628 ] although the ability to retain metal ions in solution of chitosan has been widely studied; previously reported solidstate-macromolecular complexes have been not well characterized. Particularly for several $\mathrm{Cu} /$ chitosan complexes, some X-ray and ESR studies have elucidated the resulting structures and their relationship to the parent precursor [29, 30]. Chitosan can also act as a solution template/stabilizer for nanoparticle growth [31-39]. Some biological applications [40] including biosensors for glucose have been reported, and it is found to exhibit antimicrobial properties [41]. In addition, chitosan as a support for catalytic processes has also been demonstrated [42]. We demonstrate the beneficial capability of chitosan as a solid-state template/stabilizer for nanoparticle growth, whose behavior has not yet been reported.

Poly(styrene-co-4-vinylpyridine) (PS-co-4-PVP) was selected because of effective coordinative properties of the pyridine moiety to ion metal [43]. PS-co-4-PVP is useful functional copolymer due to the vinyl pyridine block which binds metal ions and the styrene groups to facilitate stable macromolecular complexes [44-47]. PS-co-4-PVP has been used in solution as a template/stabilizer of metals and other nanoparticles [48-50]. It has also been used to aid in selective facet growth in noble metal nanoparticles [51-53]. However, PS-co-4-PVP has not been used as solid-state template for nanoparticle growth.
Here, we report a method for obtaining phase pure $\mathrm{V}_{2} \mathrm{O}_{5}$ from thermal treatment of the macromolecular complexes PS-co-4-PVP. $\left(\mathrm{VCl}_{3}\right)_{y}$ and chitosan. $\left(\mathrm{VCl}_{3}\right)_{y}$ [22]. In addition, a correlation between the size and morphology of the resulting crystals and the structural features of the macromolecular complex and the influence of both chitosan and PS-co-4-PVP are demonstrated.

\section{Experimental Procedures}

Chitosan, poly(styrene-co-4-vinylpyridine), and $\mathrm{VCl}_{3}$ were purchased from Aldrich. Chitosan (Aldrich) of low molecular weight (m.w.) was used as received. An estimation of the molecular weight was performed by viscosimetry. The average molecular weight was determined from the MarkHouwink equation and values of $[h]$ obtained using parameter previously reported by Brugnerotto et al. [54]. The determination was performed in aqueous solution in presence of $\mathrm{NaCl}$, acetic acid, and urea. The obtained value was m.w. = 61,000 for PS-co-4-PVP.

2.1. Synthesis of the Macromolecular Precursors. In a typical synthesis the $\mathrm{VCl}_{3}$ salt was added in a Schlenk tube over a $\mathrm{CH}_{2} \mathrm{Cl}_{2}$ solvent $(50 \mathrm{~mL})$ under magnetic stirring and then the respective polymer PS-co-4-PVP was added in amount according to a $1: 1,1: 5$, or $1: 10$ molar ratio for 7 days at room temperature. The molar relations indicate the initial stoichiometric relation used in the reagent and not necessarily the coordination degree of the metal in the polymeric chain.

Other details for each metallic salts reaction are given in Table 1. Subsequently, the supernatant solution was extracted with a syringe and the solid was dried under reduced pressure; see Table 1.

2.2. Pyrolysis. The pyrolysis experiments were conducted by pouring a weighed portion $(0.05-0.15 \mathrm{~g})$ of the precursors $1-$ 6 into aluminum oxide boats that were placed in a furnace (Daihan oven model Wise Therm FHP-12) under a flow of air, heating from $25^{\circ} \mathrm{C}$ to upper temperature limits of $300^{\circ} \mathrm{C}$ and then to $400^{\circ} \mathrm{C}$, followed by annealing for $2-4 \mathrm{~h}$ and at rates of $10^{\circ} \mathrm{C} \mathrm{m^{-1 }}$ in each case.

2.3. Characterization. Solid pyrolytic samples were characterized by X-ray diffraction (XRD), scanning electron microscopy (SEM), high resolution transmission electron microscopy (HRTEM), and Fourier transform infrared 
(FTIR) spectroscopy. SEM images were acquired with a Philips EM 300 scanning electron microscope. Energy dispersive X-ray analysis (EDAX) was performed on a NORAN Instruments microprobe attached to a JEOL 5410 scanning electron microscope. Additional TEM data were acquired using a JEOL SX100 and HRTEM with a JEOL 2100 TEM operating at $200 \mathrm{kV}$. The TEM samples were prepared by dispersing pyrolyzed material onto copper grids and dried at room temperature. XRD was conducted at room temperature on a Siemens D-5000 diffractometer with $\theta-2 \theta$ geometry. The XRD data was collected using $\mathrm{Cu}-\mathrm{K} \alpha$ radiation $(40 \mathrm{kV}, 30 \mathrm{~mA})$. FTIR measurements were performed on a Perkin Elmer FTIR spectrophotometer model Spectrum BXII. Thermogravimetric analysis (TGA) and differential scanning calorimetry (DSC) measurements were performed on a Mettler TA 4000 instrument and Mettler DSC 300 differential scanning calorimeter, respectively. The polymer samples were heated at a rate of $10^{\circ} \mathrm{C} / \mathrm{min}$ from ambient temperature to $1000^{\circ} \mathrm{C}$ under a constant flow of nitrogen. Photoluminescence measurements were carried out on the solid samples using a spectrofluorimeter Jasco model FP8200. A Xe lamp with shielded lamp house, $150 \mathrm{~W}$, was used as the excitation source. The optical absorbance was measured using a UV-vis absorption spectrophotometer (Shimadzu UV-2460 with a solid sampler).

\section{Results and Discussion}

3.1. Synthesis of the Precursors. Macromolecular complexes PS-co-4-PVP. $\left(\mathrm{VCl}_{3}\right)_{y}$ and chitosan $\cdot\left(\mathrm{VCl}_{3}\right)_{y}$ are green to violet solids (see supporting information $\mathrm{S}_{1}$ in Supplementary Material available online at http://dx.doi.org/10.1155/2015/ 105157). Characterization was achieved by elemental analysis, IR spectroscopy, and TGA/DSC analysis detailing the degree coordination of the metal to the polymeric chain. A coordination degree in the range $37-90 \%$ was estimated and the data are (1) $90 \%$, (2) $89 \%$, (3) $37 \%$, (4) 55\%, (5) 62\%, and (6) $42 \%$. Due to the insoluble nature of the solid products and their paramagnetic nature $\left(\mathrm{V}^{+3}, \mathrm{~d}^{2}\right.$ ions) few techniques are available to characterize these solids.

For the PS-co-4-PVP. $\left(\mathrm{VCl}_{3}\right)_{y}$ macromolecular complexes, the presence of more metal centers incorporated in the polymeric chain, that is, the 1:1 molar ratio, produced a largely woven polymer structure compared to a 1:10 molar ratio. In this latter case, the presence of fewer metals produced a more linear polymer chain structure. Additionally in the IR spectra a new band is found, centered at $1615 \mathrm{~cm}^{-1}$ and assigned to the pyridine ring $[22,43]$, which is typical of pyridine coordination.

For the chitosan $\left(\mathrm{VCl}_{3}\right)_{\text {y }}$ macromolecular complexes a less regular situation holds. TGA analyses, see supporting information $\mathrm{S}_{2}$, show a large weight loss at $\sim 280^{\circ} \mathrm{C}$ for the chitosan $\cdot\left(\mathrm{VCl}_{3}\right)_{y}$ precursors and at $360^{\circ} \mathrm{C}$ for the PSco-4-PVP. $\left(\mathrm{VCl}_{3}\right)_{y}$, both corresponding to the carbonization of the organic matter [55]. DSC profiles (supporting information $\mathrm{S}_{2}$ ), exhibited exothermic peaks at $400^{\circ} \mathrm{C}$ for chitosan. $\left(\mathrm{VCl}_{3}\right)_{y}$ precursors and at $500^{\circ} \mathrm{C}$ for
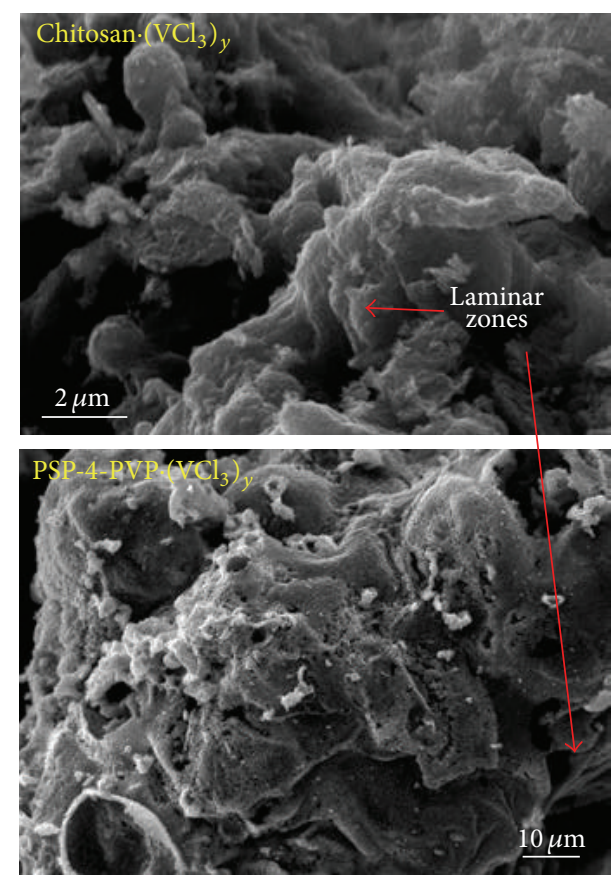

FIGURE 1: SEM image of pyrolytic products from PS-co-4PVP. $\left(\mathrm{VCl}_{3}\right)_{y}$ and chitosan. $\left(\mathrm{VCl}_{3}\right)_{y}$ both in molar ratio 1:1. Red arrows indicate the underlying layered structure within the pyrolyzed material.

PS-co-4-PVP. $\left(\mathrm{VCl}_{3}\right)_{y}$ precursors corresponding to the combustion of the organic matter [55]. The total weight loss for these two precursors indicates a \% of coordination of $\sim 86 \%$ for chitosan. $\left(\mathrm{VCl}_{3}\right)_{y}$ and close to $100 \%$ for PS-co-4PVP. $\left(\mathrm{VCl}_{3}\right)_{y}$. DSC analyses for PS-co-4-PVP. $\left(\mathrm{VCl}_{3}\right)_{y}$ exhibit the corresponding carbonization peak at $\sim 400^{\circ} \mathrm{C}$. In the IR spectra the broad $v(\mathrm{OH})$ in chitosan $[22,31]$ observed at $3280 \mathrm{~cm}^{-1}$ becomes unfolded upon coordination, appearing as a new band at $\sim 3100 \mathrm{~cm}^{-1}$.

3.2. Characterization of the Pyrolytic Products. Pyrolytic products are orange to yellow stable solids (see supporting information $\mathrm{S}_{1}$ ). The X-ray diffraction (XRD) of the as prepared $\mathrm{V}_{2} \mathrm{O}_{5}$ nanostructures from all the precursors shows diffraction peaks that can be perfectly indexed to the orthorhombic system. The primary reflections are observed at (200), (001), (110), (301), (310), (600), and (020). A representative XRD is shown in Figure $\mathrm{S}_{3}$ supporting information for the 1:1 PS-co-4-PVP. $\left(\mathrm{VCl}_{3}\right)_{y}$ and chitosan $\cdot\left(\mathrm{VCl}_{3}\right)_{y}$ precursors. No peaks of any other phase were detected, indicating the high purity of the products. A representative SEM image for the pyrolytic product from chitosan $\left(\mathrm{VCl}_{3}\right)_{y}$ compared with those for PS-co-4-PVP. $\left(\mathrm{VCl}_{3}\right)_{y} 1: 1$ is shown in Figure 1. For the chitosan $\cdot\left(\mathrm{VCl}_{3}\right)_{y}$ pyrolytic precursors the resulting compound has an agglomerated appearance comprising clumps of layered vanadium pentoxide, a morphology typical of many oxides [1-8] that are not templated, or without conditions to control the thermodynamics of the crystal growth anisotropy. 


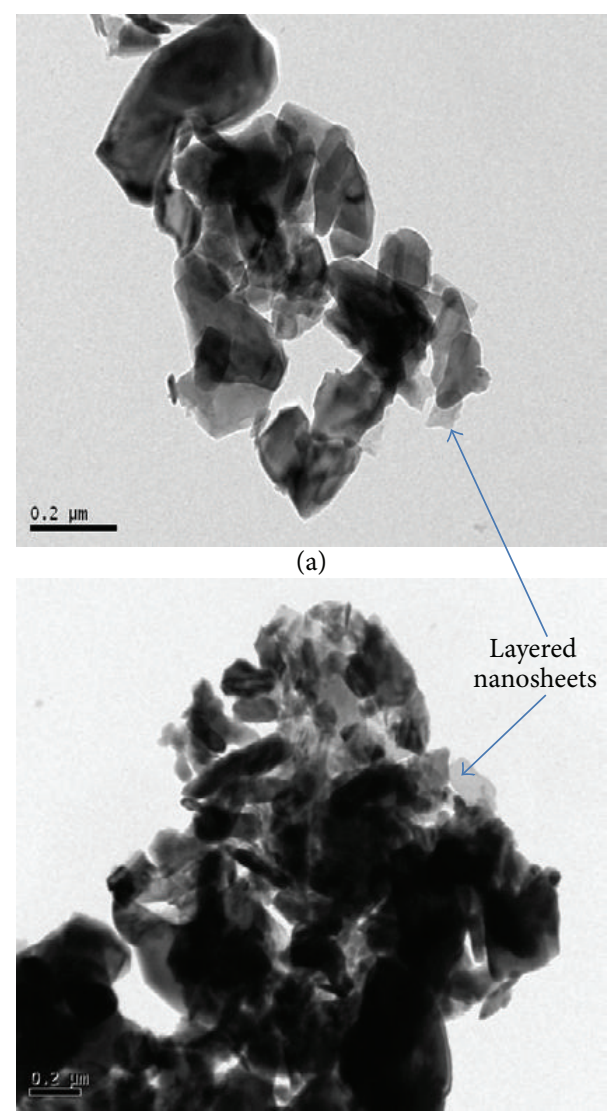

(c)

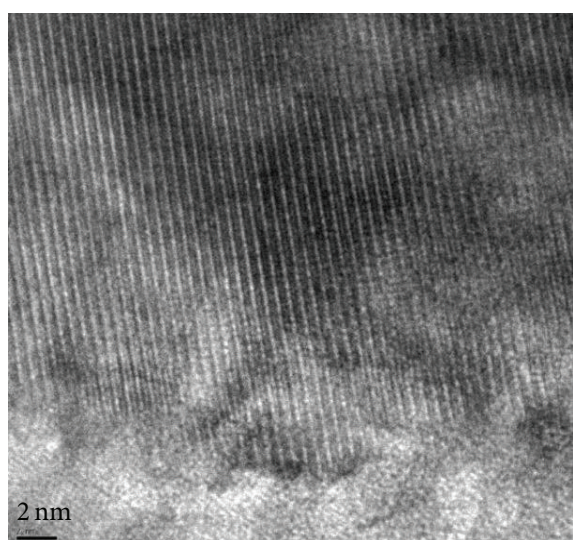

(b)
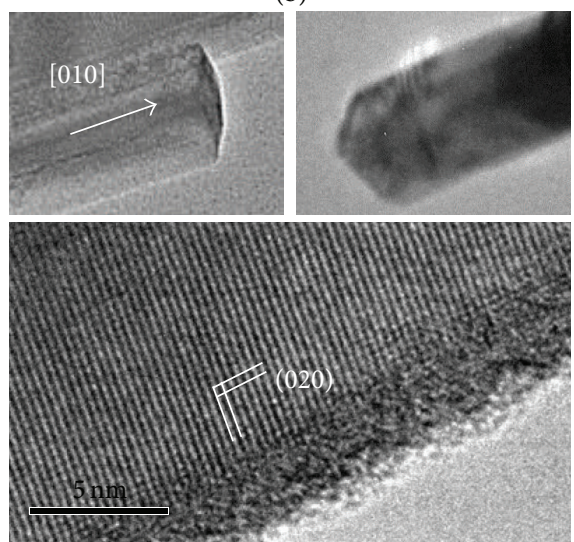

(d)

FIGURE 2: TEM and HRTEM images of the of pyrolytic products from ((a), (b)) 1:1 PS-co-4-PVP· $\left(\mathrm{VCl}_{3}\right)_{n}$ and $((\mathrm{c}),(\mathrm{d})) 1: 1 \mathrm{chitosan} \cdot\left(\mathrm{VCl}_{3}\right)_{n}$.

Both morphologies exhibit some degree of porosity. However, for PS-co-4-PVP. $\left(\mathrm{VCl}_{3}\right)_{y}$ precursor, a characteristic fused grain structure is observed by HRTEM analysis in Figure 2. The nanofiber filaments exhibit characteristic single-crystal structure with elongation parallel to the $a-b$ axis of the $\mathrm{V}_{2} \mathrm{O}_{5}$ layered unit cell structure. From HRTEM examination of terminating surfaces, these nanorods are found to grow along the [010] direction and terminated by a small $\{001\}$ surface flanked on either side by $\{310\}$ facets (see Figure 2(d)). Characteristically, the terminating edges are triplanar as shown in Figure 2(d) and terminated with a set of (310) surfaces on either side of the (010) surface. Similar $\mathrm{V}_{2} \mathrm{O}_{5}$ nanorods have been observed from solution preparation methods $[4,5,10]$.

For the pyrolysis of the $1: 5$ chitosan $\cdot\left(\mathrm{VCl}_{3}\right)_{y}$ precursor, $\mathrm{V}_{2} \mathrm{O}_{5}$ nanoparticles with $8-30 \mathrm{~nm}$ with a mean of $16 \mathrm{~nm}$ were observed as shown in Figure 3.

For the product from the pyrolysis of 1:5 PS-co4-PVP. $\left(\mathrm{VCl}_{3}\right)_{y}$, larger crystals with layered structure are observed, as shown in Figure 4(a). The decomposition of the precursor in this case results in mesoporous layered $\mathrm{V}_{2} \mathrm{O}_{5}$ materials. Similar mesoporous $\mathrm{V}_{2} \mathrm{O}_{5}[7,10]$ and $\mathrm{V}_{2} \mathrm{O}_{5}$ supported over other metal oxides have been reported [5759]. The copolymer mixture facilitates a mechanism that allows bridged nanocrystals of $\mathrm{V}_{2} \mathrm{O}_{5}$ throughout the layered structure of the larger crystals to induce a disordered

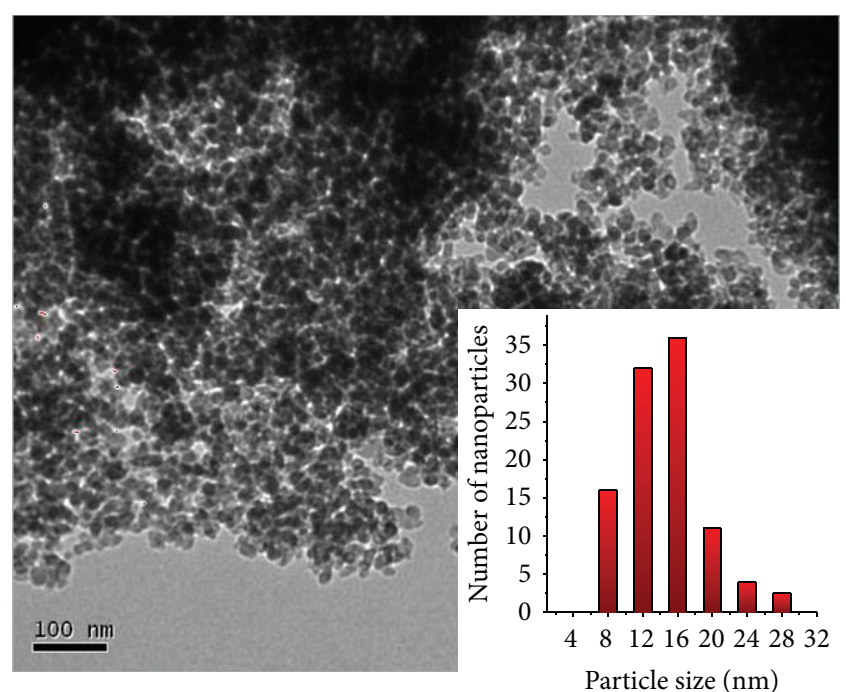

FIGURE 3: TEM image of pyrolytic product from chitosan $\cdot\left(\mathrm{VCl}_{3}\right)_{y}$ $(1: 5)$ and their histogram, inset.

mesoporous structure. This approach is made possible by clustering of $\mathrm{V}$-species and subsequent decomposition of the organic phase to form holes within the crystallizing $\mathrm{V}_{2} \mathrm{O}_{5}$ material. 


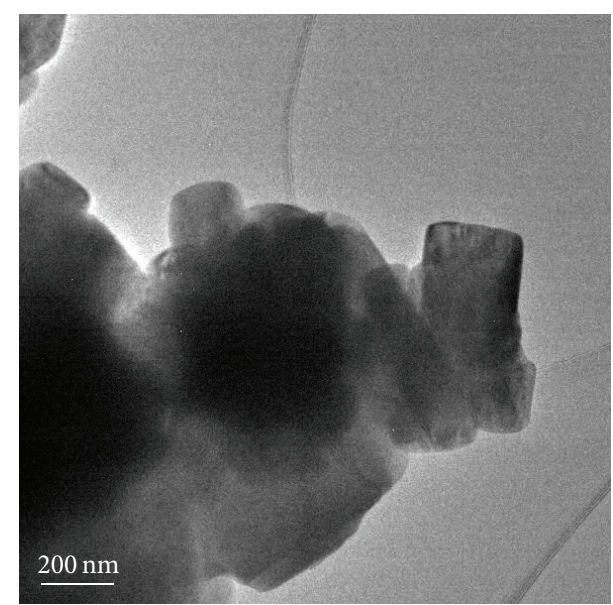

(a)

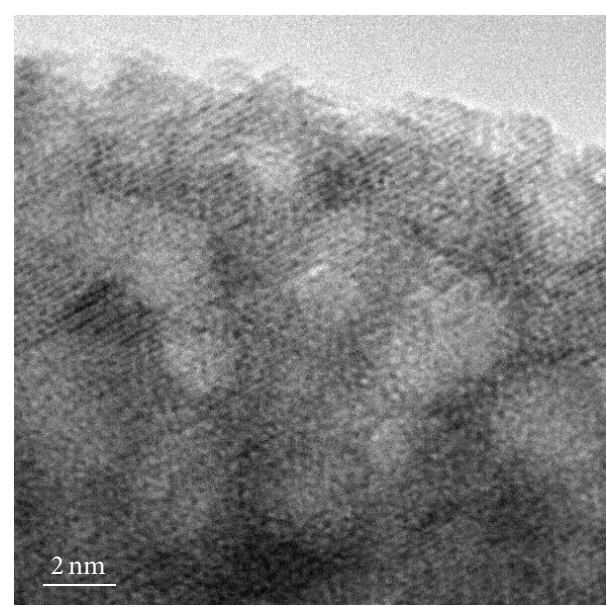

(b)

FIGURE 4: (a) TEM image of the pyrolytic precursor from 1:5 PS-co-4-PVP-(VCl 3$)_{y}$ and (b) HRTEM of a mesoporous laminar zone.

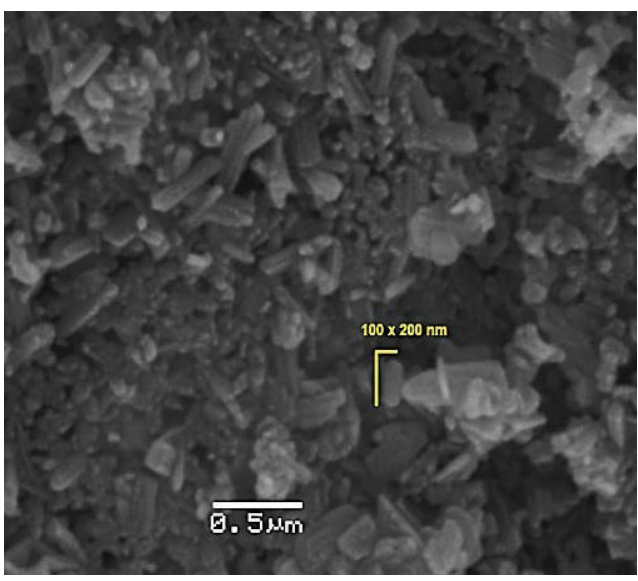

(a)

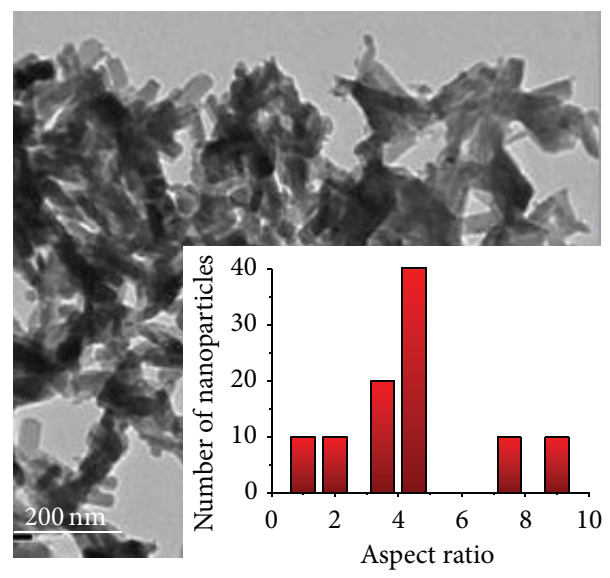

(b)

FIGURE 5: SEM (a) and TEM (b) image of the pyrolytic product from chitosan $\left(\mathrm{VCl}_{3}\right)_{y}(1: 10)$ precursor.

For the pyrolytic product from the precursor chitosan. $\left(\mathrm{VCl}_{3}\right)_{y}(1: 10)$, nanobelts were observed (Figures 5 and 2(d)). The size dispersion histogram, inset in Figure 5(b), shows a mean aspect ratio of 4.5 for these nanobelts.

A summary of the morphology and size of the pyrolytic products is presented in Table 2 from solid-state procedures $[60,61]$. As discussed mechanistically further below, the nanorod growth avoids sintering and coalescence due to the carbon-based templates formed from combustion of the organic matter but allows sufficient space for elongation of the structures.

A fluidized bed approach to annealing has been reported to alleviate issues of unwanted size variance caused by sintering, allowing $\mathrm{kg}$-scale quantities of nanomaterials to be formed. In our case, the macromolecular templating methodology allows nanomaterial formation without dominating sintering using specific macromolecular complexes in certain molar ratios with the metal oxide precursor.
3.3. Formation Mechanism. Although the formation of nanoparticles in solution is known [62-65], the formation mechanism in solid-state is lacking $[60,61]$. The most probable mechanism of the formation of the here prepared solidstate $\mathrm{V}_{2} \mathrm{O}_{5}$ nanostructures can be compared to comparative investigations [65].

The first step on heating involves the formation of a 3D network to produce a thermal [65] stable matrix. This step is crucial to offset sublimation. For instance, ferrocene undergoes sublimation on heating at $483 \mathrm{~K}$ (the melting point), but in presence of oxalic acid nanoparticles of $\mathrm{Fe}_{2} \mathrm{O}_{3}$ nanoparticles were formed [66]. In our system the first heating step could involve a cross-linking of the chitosan and PSco-4-PVP polymers (precursor 1-3 and 4-6, resp.) to give a $3 \mathrm{D}$ matrix containing $\mathrm{O}-\mathrm{M}-\mathrm{O}$ and $\mathrm{H}_{2} \mathrm{~N}-\mathrm{M}-\mathrm{NH}_{2}$ links (for the chitosan polymer) and (pyridine) N-M-N(pyridine) bonds for the PS-co-4-PVP polymer. A schematic representation of this process is provided in Figure 6. The following steps involve the starting of the organic carbonization, producing 
TABLE 2: Summary of the morphology and size for $\mathrm{V}_{2} \mathrm{O}_{5}$ obtained from the PS-co-4-PVP. $\left(\mathrm{VCl}_{3}\right)_{y}$ and chitosan $\left(\mathrm{VCl}_{3}\right)_{y}$ precursors in molar ratios $1: 1,1: 5$, and $1: 10$.

\begin{tabular}{lcc}
\hline Ratio M/polymer & Morphology (SEM) & Shape, Size (TEM) \\
\hline V/chitosan $(1: 1)$ & Porous laminar, irregular & Irregular NPs, $30-50 \mathrm{~nm}$ \\
V/chitosan $(1: 5)$ & Regular nanorods, $50 \mathrm{~nm} \times 2 \mu \mathrm{m}$ & Regular, $16 \mathrm{~nm} \varnothing$ \\
V/chitosan $(1: 10)$ & Micro- and nanorods, $100-200 \mathrm{~nm}$ & Nanobelts, $30-60 \mathrm{~nm}$ \\
V/PS-co-4-PVP $(1: 1)$ & Porous & Irregular NPs, $10-25 \mathrm{~nm} \emptyset$ \\
V/PS-co-4-PVP $(1: 5)$ & Irregular sheets & Agglomerates \\
V/PS-co-4-PVP $(1: 10)$ & Laminar zones & Irregular cubic NPs, agglomerates \\
\hline
\end{tabular}

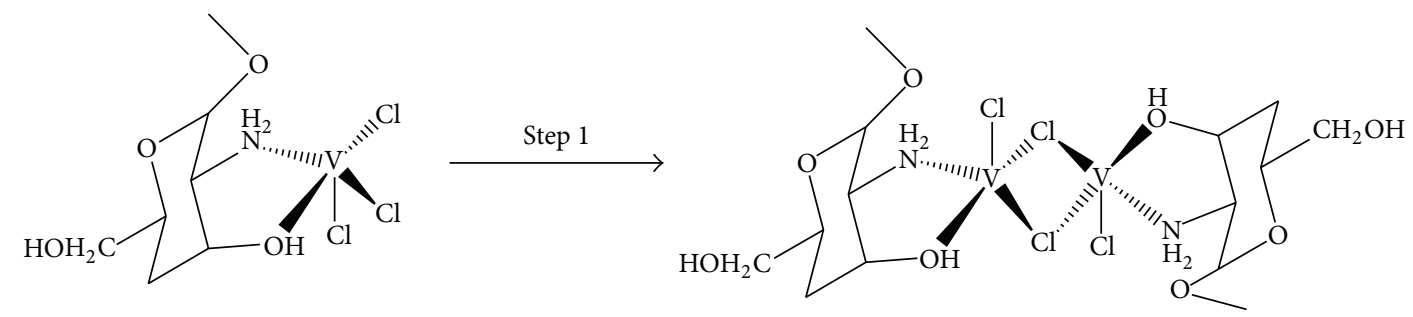

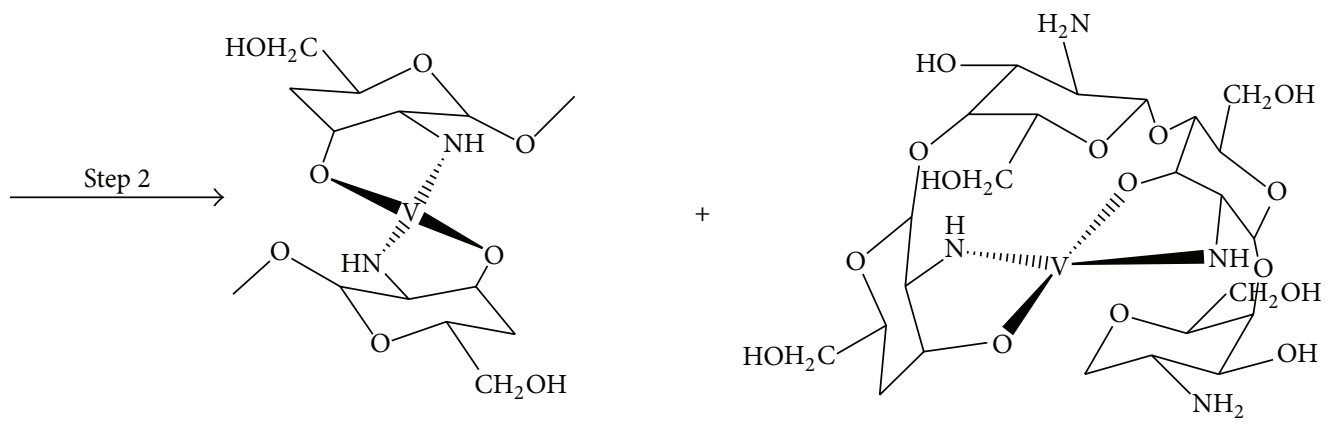

Matrix

(a)

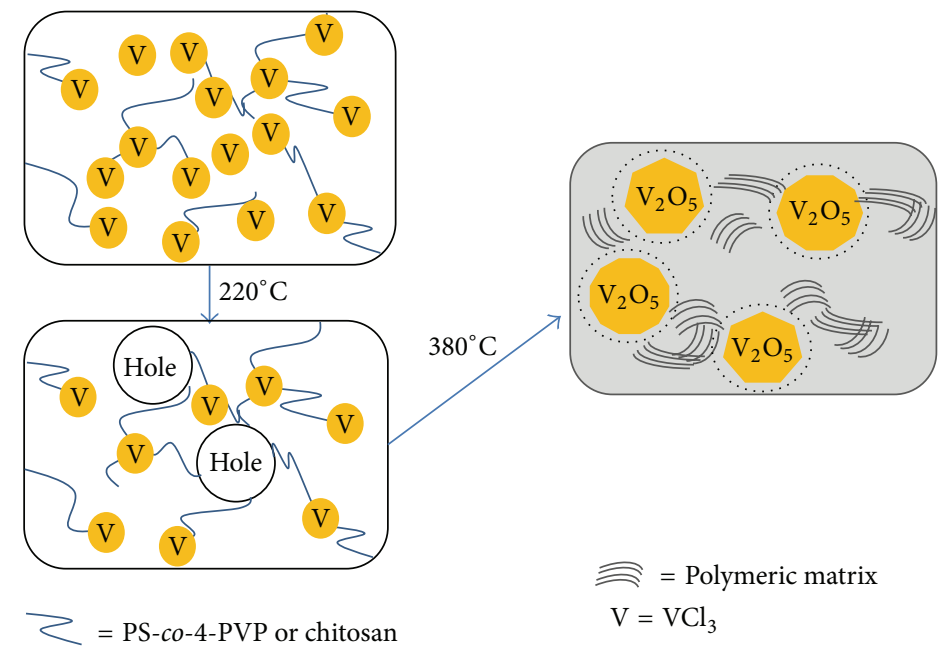

(b)

FIGURE 6: Possible coordination modes of the $\mathrm{VCl}_{3}$ salt to the chitosan polymeric chain (a) and schematically proposed formation mechanism of the $\mathrm{V}_{2} \mathrm{O}_{5}$ materials and structures (b). 


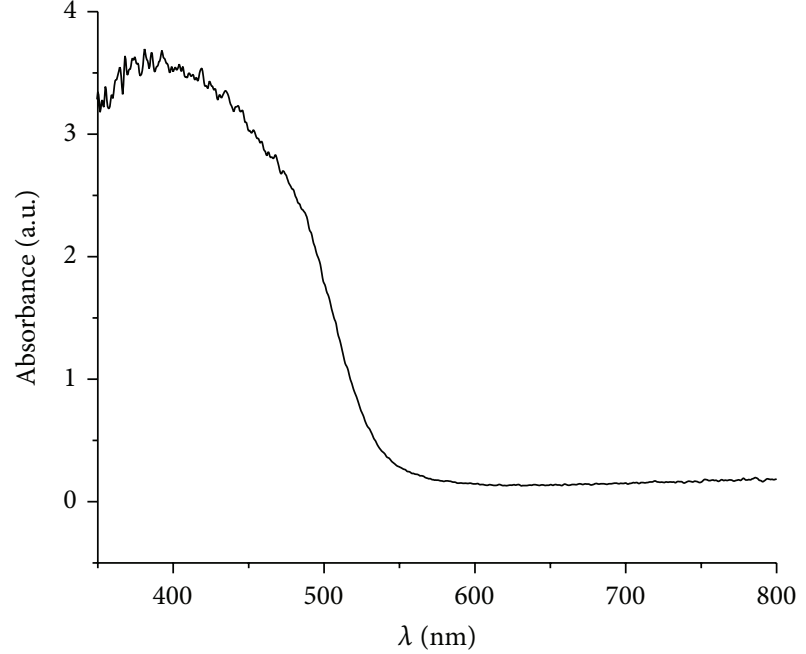

— PS-b-4-PVP $\left(\mathrm{VCl}_{3}\right)_{n}$

(a)

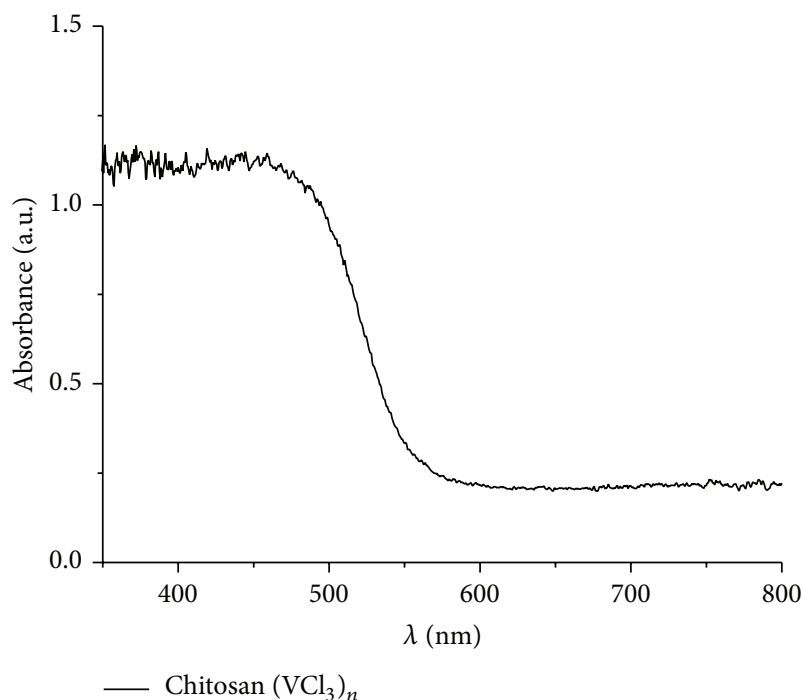

(c)

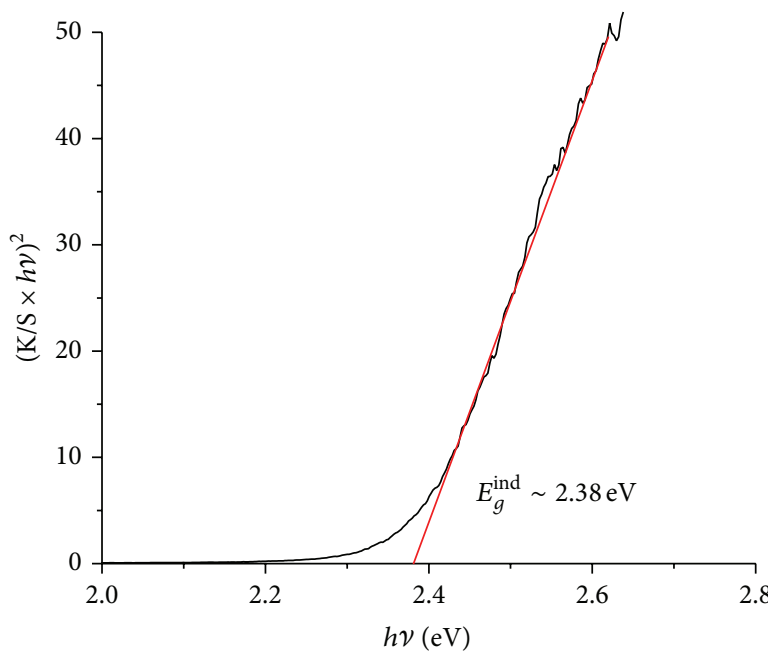

- PS-b-4-PVP $\left(\mathrm{VCl}_{3}\right)_{n}$

(b)

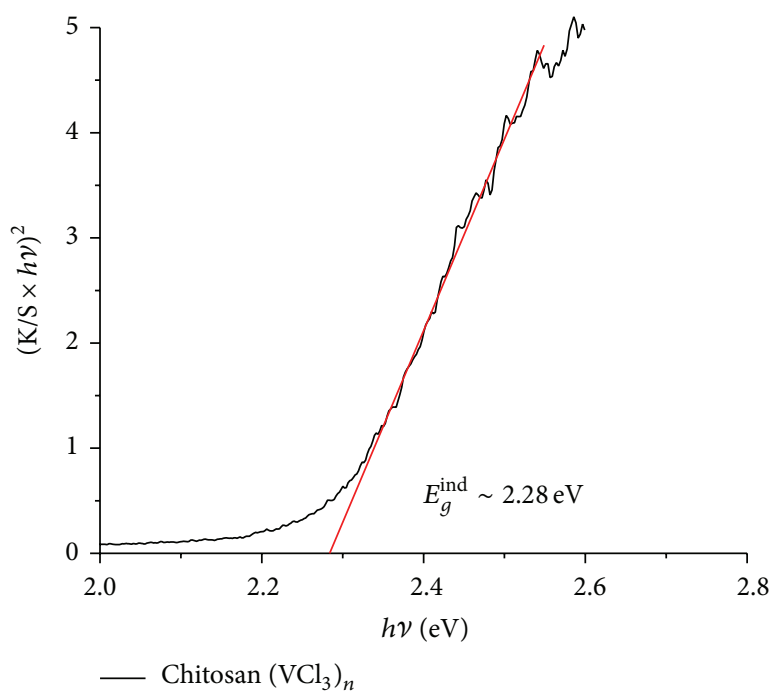

(d)

Figure 7: ((a), (c)) Absorption and ((b), (d)) Tauc et al. [56] plot of the pyrolytic products from PS-co-4-PVP. $\left(\mathrm{VCl}_{3}\right)_{y}$ and chitosan· $\left(\mathrm{VCl}_{3}\right)_{y}$, respectively.

holes where the nanoparticles begin to nucleate. According to TG/DSC analysis this occurs at $\sim 400^{\circ} \mathrm{C}$ for the chitosan and at $360^{\circ} \mathrm{C}$ for PS-co-4-PVP polymer matrices. Simultaneously the oxygen of the air oxidizes the $\mathrm{V}(\mathrm{III})$ of $\mathrm{VCl}_{3}$ salt to $\mathrm{V}(\mathrm{V})$ with the formation of $\mathrm{V}_{2} \mathrm{O}_{5}$ that nucleates inside the holes formed by the combustion of the organic matter. In this intermediate stage a layered graphitic carbon host was detected in our previous work [60] that acts as template where the nanoparticles can coalesce and crystallize into their respective morphologies. After complete combustion this template is fully decomposed, forming a residual carbon that appears as an ultrathin carbon shell surrounding the nanoparticles [52]. In cases where layered vanadia are formed, these structures are less restricted by the template structure, allowing a layered xerogel-like material to form.
3.4. Absorption and Luminescence Characteristics of $\mathrm{V}_{2} \mathrm{O}_{5}$. Transition metal oxides with diverse morphological structure have a wide range of potential applications that benefit from specific photophysical properties. $\mathrm{V}_{2} \mathrm{O}_{5}$ can exhibit persistent photocurrent, indirect allowed optical transitions, electrochromism [67], and several other phenomena that can be controlled through variation in multiple valence state control, structure, and phase by different synthetic protocols.

The UV-vis data indicate a similar behavior to that found in previous studies [68-77]. The maxima absorption was observed in the range $380-450 \mathrm{~nm}$. Figure 7 shows the absorbance and the corresponding Tauc plot [56] for the pyrolytic products from the macromolecular precursors PS-co-4-PVP. $\left(\mathrm{VCl}_{3}\right)_{y}$ and chitosan. $\left(\mathrm{VCl}_{3}\right)_{y}$ in a $1: 1$ molar ratio. The estimated band gap values are found in 
TABLE 3: Optical transition energy for $\mathrm{V}_{2} \mathrm{O}_{5}$ from several morphologies and preparation methods.

\begin{tabular}{|c|c|c|c|c|}
\hline Form & Band gap (eV) & Method & Comments & Reference \\
\hline Macroplates & 3.4 & $\begin{array}{c}\mathrm{V}_{2} \mathrm{O}_{5} \text { in a water/ethanol } \\
\text { media }\end{array}$ & $\begin{array}{l}\text { Macroplates of } 10-11 \mu \text { length } \\
\text { by } 5-6 \mu\end{array}$ & [19] \\
\hline Nanosheets & 2.25 & Surfactant sol-gel & Crystal size $52 \mathrm{~nm}$ & {$[91]$} \\
\hline Nanoribbon & 2.3 & Magnetron sputtering & Thin thickness $34-70 \mathrm{~nm}$ & [1] \\
\hline Nanoparticles & 2.85 & $\mathrm{VOCl}_{3} / \mathrm{PEG}$ & Particle size 25-30 nm & {$[79]$} \\
\hline Nanoparticles & 2.93 & $\mathrm{NH}_{4} \mathrm{VO}_{3} /$ microemulsion & Particle size 5-8 nm & {$[92]$} \\
\hline Flower-like & 2.3 & Hydrothermal & - & {$[70]$} \\
\hline Nanorods & $2.30-2.60$ & Magnetron sputtering & Annealed at $500^{\circ} \mathrm{C}$ & {$[68]$} \\
\hline Film & $2.51-2.53$ & Pulsed laser deposited & Thin thickness $28-22 \mathrm{~nm}$ & {$[71,93]$} \\
\hline Film & $2.21-2.22$ & Magnetron sputtering & Thin thickness $35-70 \mathrm{~nm}$ & {$[94]$} \\
\hline Film & $2.12-2.47$ & Pulsed laser deposition & Thin thickness $300 \mathrm{~nm}$ & {$[67]$} \\
\hline Film & $2.42-2.49$ & Sol-gel & Thin thickness $0.22-0.34 \mathrm{~nm}$ & [69] \\
\hline Film & $2.50-2.66$ & Evaporation & Thin thickness $17 \mathrm{~nm}$ & {$[70]$} \\
\hline Film & $1.50-3.00$ & Plasma, CVD & Thin thickness $75-138 \mathrm{~nm}$ & {$[71]$} \\
\hline Film & $2.30-2.50$ & Spray pyrolysis & Thin thickness $30-55 \mathrm{~nm}$ & {$[72]$} \\
\hline Film & $2.29-2.34$ & Physical VD & $\begin{array}{l}\text { Thin thickness } 45,74 \text {, and } \\
\qquad 164 \mathrm{~nm}\end{array}$ & {$[73]$} \\
\hline Film & 2.24 & Sputtering & $\begin{array}{l}\mathrm{V}_{2} \mathrm{O}_{5} \text { target on } \mathrm{SnO}_{2}: \text { Thin } \\
\text { thickness } 35-160 \mathrm{~nm}\end{array}$ & {$[74]$} \\
\hline Film & 2.2 & Thermally evaporated & Thin thickness $50-215 \mathrm{~nm}$ & {$[75]$} \\
\hline Film & $2.03-2.62$ & $\begin{array}{c}\text { Thermal evaporation and } \\
\text { Annealing at } 350^{\circ} \mathrm{C}\end{array}$ & Lithium intercalation & {$[76]$} \\
\hline Film & $2.25-2.37$ & RF sputtering & Target in $\mathrm{O}_{2}$ & {$[77]$} \\
\hline Layered nanosheets ${ }^{(\mathrm{a})}$ & 2.34 & Solid-state pyrolysis & & \\
\hline Layered nanosheets ${ }^{(\mathrm{b})}$ & 2.4 & Solid-state pyrolysis & & This work \\
\hline Larger crystals with layered structure ${ }^{(c)}$ & 2.4 & Solid-state pyrolysis & & \\
\hline nanoparticles $^{(\mathrm{d})}$ & 2.34 & Solid-state pyrolysis & Average size $16 \mathrm{~nm}$ & \\
\hline
\end{tabular}

the range $2.2-2.4 \mathrm{eV}[59,68-77]$ corresponding to allowed indirect optical transitions. Owing to indirect transitions, quantum confinement effects from reduced grain sizes in the as-synthesized $\mathrm{V}_{2} \mathrm{O}_{5}$ [56] are not observed to dominate absorbance characteristics when accounting for scattering processes.

It has been found that the absorption properties and band gap values of nanostructured $\mathrm{V}_{2} \mathrm{O}_{5}$ depend on their shape and size (also some dependence on the experimental condition and preparation method of the sample). The most studied $\mathrm{V}_{2} \mathrm{O}_{5}$ materials are the film systems [67-72, 74]. To discuss the absorption data obtained in our work, we have selected several data from literature, summarized in Table 3 [68-76]. Relatively few data for $\mathrm{V}_{2} \mathrm{O}_{5}$ morphologies other than film have been reported $[56,67,69-75,78]$.

For films the band gap energy is in the range $2-2.6 \mathrm{eV}$. The energy depends strongly on the thin thickness. Considering that the bang gap for $\mathrm{V}_{2} \mathrm{O}_{5}$ bulk is $2.0 \mathrm{eV}$ the blue shift of thin films may be due to the decrease of the materials in one direction to give a film. The band gap of the other than film $\mathrm{V}_{2} \mathrm{O}_{5}$ nanostructures appears to increase the band gap energies values as can be viewed from Table 3. Also the creation of $\mathrm{V}^{4+}$ sites produce deficiency of oxygen in turn provoking an increase of the band gap. Our band gap data, values in the range $2.3-2.4 \mathrm{eV}$, are in good agreement with those collected in Table 3. Data could be consistent with film and also with some nanostructures as nanoribbons, nanorods, and nanosheets, all of these morphologies detected in the pyrolytic product of some precursors of $\mathrm{V}_{2} \mathrm{O}_{5}$.

In spite of the thermal procedure to obtain the nanostructured $\mathrm{V}_{2} \mathrm{O}_{5}$ the optical properties are in agreement with those of $\mathrm{V}_{2} \mathrm{O}_{5}$ obtained using low/ambient temperature procedures [79]. Annealing methods usually result in decreasing of the band gap values by enhancing of the grain size and eliminating confinement effects.

Luminescence spectra for the resulting $\mathrm{V}_{2} \mathrm{O}_{5}$ formed through thermolytic methods are shown in Figure 8 . Several reports of photoluminescence $(\mathrm{PL})$ of $\mathrm{V}_{2} \mathrm{O}_{5}$ in several morphologies including spheres, nanobelts, nanoribbons, nanowires, nanodandelions, nanofibers, films, and $\mathrm{V}_{2} \mathrm{O}_{5}$ included in solid matrix have been reported, summarized in Table $4[49,69,80-86]$. These studies reveal that the emission 


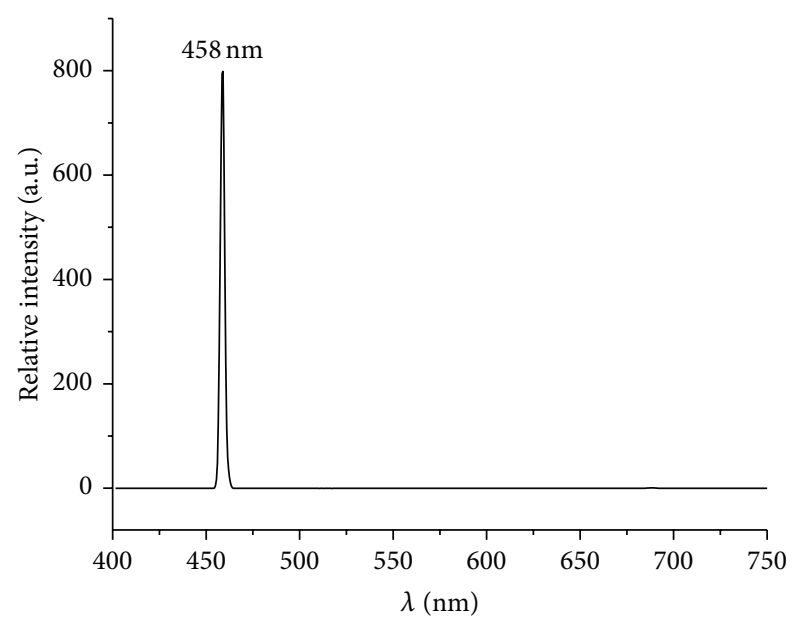

(a) $\lambda_{\text {exc }}=420 \mathrm{~nm}$

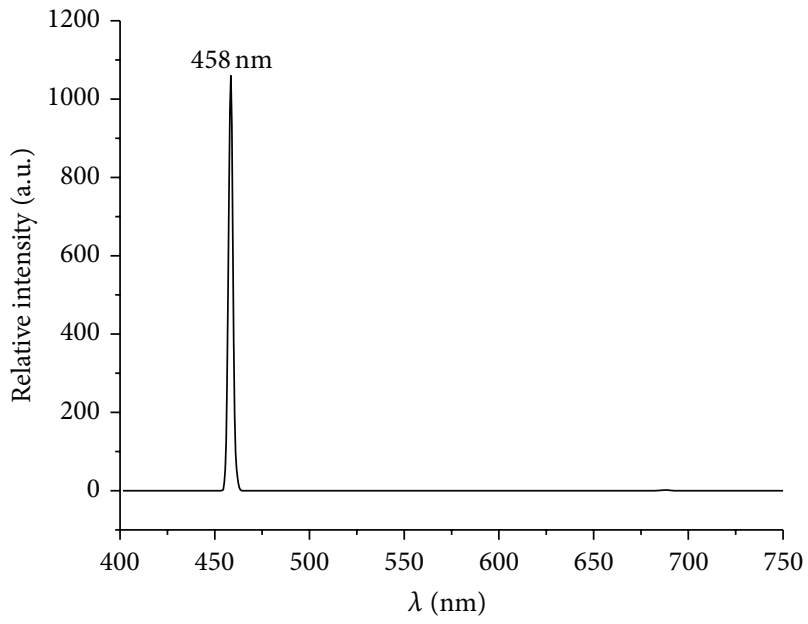

(c) $\lambda_{\text {exc }}=420 \mathrm{~nm}$

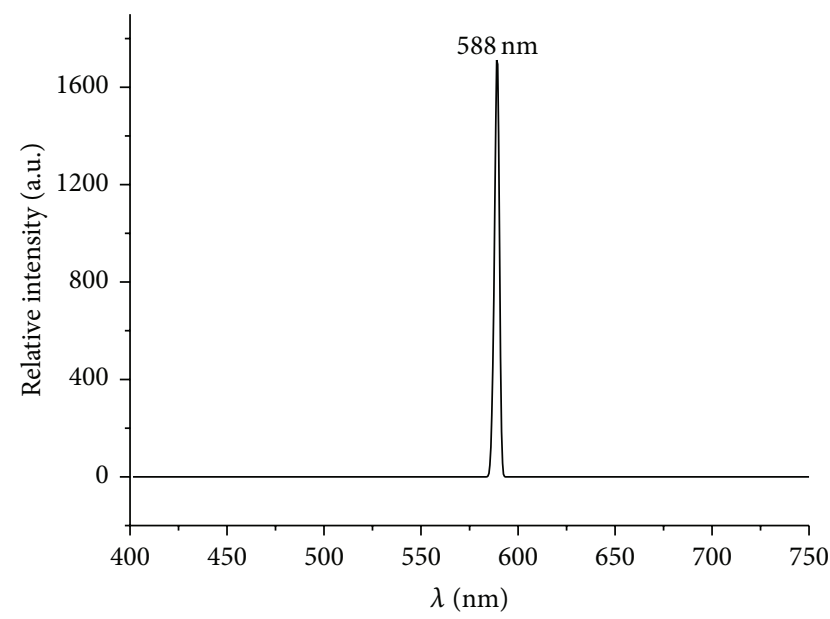

(b) $\lambda_{\text {exc }}=560 \mathrm{~nm}$

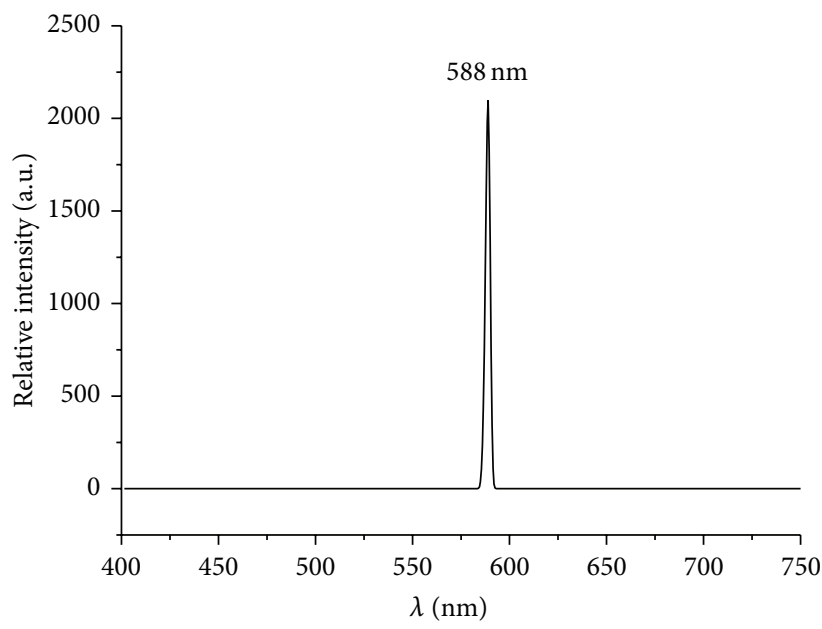

(d) $\lambda_{\text {exc }}=560 \mathrm{~nm}$

Figure 8: (a) Emission, (b) spectra of the pyrolytic products from PS-co-4-PVP. $\left(\mathrm{VCl}_{3}\right)_{y}$, and ((c), (d)) from pyrolytic products from chitosan $\cdot\left(\mathrm{VCl}_{3}\right)_{y}$ at two different excitation energies.

maxima are highly dependent on the morphology and on the surrounding environment such as $\mathrm{SiO}_{2}, \mathrm{TiO}_{2}$, and other solid matrixes $[85,86]$.

The observed PL spectra of the PS-co-4-PVP. $\left(\mathrm{VCl}_{3}\right)_{y}$ and chitosan $\left(\mathrm{VCl}_{3}\right)_{\text {y }}$ pyrolytic product are showed in Figure 8. The intense and sharp emission peak observed at $458 \mathrm{~nm}$ is assigned to the near band edge that is assigned to transitions of electrons between valence $(\mathrm{O}-2 \mathrm{p})$ and conduction band (V-3d) and usually observed for $\mathrm{V}_{2} \mathrm{O}_{5}[79,87,88]$. On the other hand the emission peak observed at $588 \mathrm{~nm}$ is caused by the surface defects and also observed for $\mathrm{V}_{2} \mathrm{O}_{5}$ using several preparation methods $[49,69]$. Additionally, an intense emission peak was observed at $731 \mathrm{~nm}$ (see supporting information $\mathrm{S}_{4}$ ) with an excitation energy of $364 \mathrm{~nm}$ which has also been observed for $\mathrm{V}_{2} \mathrm{O}_{5}$ obtained using solution method [80, 89]. This emission has been assigned to the presence of oxygen vacancies [90] and in our case due to the thermal high temperature preparation method that is known to provoke an increase of the oxygen vacancies $[49,70]$.
As previously mentioned [90], this material appears to be a suitable candidate for application in gas sensing devices.

\section{Conclusions}

The present study describes a novel and facile solvent-less process for the preparation of pure $\mathrm{V}_{2} \mathrm{O}_{5}$ by solid-state pyrolysis of easily prepared macromolecular complexes. The characteristics of the macromolecular complexes precursors, as nature of the polymer and metal/polymer ratio, are crucial in determining the morphology and particle size of the pyrolytic products. The chitosan polymer acting as the solid-state template can facilitate single-crystal nanobelt structures. For the pyrolytic products from chitosan $\left(\mathrm{VCl}_{3}\right)_{y}$ (1:5) nanoparticles with means diameters of $\sim 15 \mathrm{~nm}$ are possible. This result suggests the possibility of morphology control through a solid-state synthetic method, without requiring capping ligands, or necessitates additive organics or ions to influence crystal growth habit. The morphology and 
TABle 4: Photoluminescence data for $\mathrm{V}_{2} \mathrm{O}_{5}$ in several morphologies.

\begin{tabular}{|c|c|c|c|c|}
\hline Morphology & $\lambda_{\text {lum }}(\mathrm{nm})$ & $\Lambda_{\text {exc. }}(\mathrm{nm})$ & Comments & Reference \\
\hline Film & 399 & 325 & & {$[82]$} \\
\hline Film & 500 & 300 & & {$[83]$} \\
\hline Nanowires & 391, 629, and 698 & 325 & & {$[82]$} \\
\hline Nanospheres & 391 & 325 & & {$[82]$} \\
\hline Nanoparticles & 460,593 & 380 & Particle size 5-8 nm & [49] \\
\hline Nanoparticles & 495,595 & 420 & Particle size $25-30 \mathrm{~nm}$ & [69] \\
\hline Cylindrical & $626-652$ & - & $3-5 \mu \mathrm{m}$ diameter fibers & {$[80]$} \\
\hline Dandelions & 399,423 , and 440 & - & & {$[81]$} \\
\hline $\mathrm{TiO}_{2}$ supported film & 469,523 & 325 & & {$[84]$} \\
\hline $\mathrm{V}_{2} \mathrm{O}_{5}$ supportedon $\mathrm{SiO}_{2}$ & 515 & 290 & & {$[85]$} \\
\hline $\mathrm{V}_{2} \mathrm{O}_{5}$ supportedon $\mathrm{TiO}_{2}$ & 550 & 370 & & {$[85]$} \\
\hline $\mathrm{V}_{2} \mathrm{O}_{5}$ supportedon $\mathrm{Al}_{2} \mathrm{O}_{3}$ & 580 & 315 & & {$[85]$} \\
\hline $\mathrm{V}_{2} \mathrm{O}_{5}$ supportedon $\mathrm{MgO}$ & 590 & 282 & & {$[85]$} \\
\hline $\mathrm{V}_{2} \mathrm{O}_{5}$-doped & 425 & 280 & & {$[86]$} \\
\hline $\mathrm{V}_{2} \mathrm{O}_{5}$ & 458 & 420 & Layered nanosheets & \\
\hline $\mathrm{V}_{2} \mathrm{O}_{5}$ & 588 & 560 & & \\
\hline $\mathrm{V}_{2} \mathrm{O}_{5}$ & 458 & 420 & NPs with average size $16 \mathrm{~nm}$ & This work \\
\hline $\mathrm{V}_{2} \mathrm{O}_{5}$ & 588 & 560 & & \\
\hline $\mathrm{V}_{2} \mathrm{O}_{5}$ & 458 & 420 & $\begin{array}{l}\text { Larger crystals with layered } \\
\text { structure }\end{array}$ & \\
\hline $\mathrm{V}_{2} \mathrm{O}_{5}$ & 588 & 560 & & \\
\hline
\end{tabular}

particle size are modulated by the ratio of the metal source and the nature of the polymer. An intense emission in the visible range linked to oxygen defect contributions suggests the potential application as oxygen sensing materials. These results highlight a way to control size and morphologies of $\mathrm{V}_{2} \mathrm{O}_{5}$ nanoparticles and structures in the solid-state.

\section{Conflict of Interests}

The authors declare no competing interests.

\section{Acknowledgments}

Project Fondecyt 1120179 is acknowledged for financial support. This work was also supported by the Irish Research Council New Foundations Award.

\section{References}

[1] P. Davidson, "Vanadium pentoxide gels: from 'chimie douce' to 'matière molle,' Comptes Rendus Chimie, vol. 13, no. 1-2, pp. 142153, 2010.

[2] J. Livage, "Vanadium pentoxide gels," Chemistry of Materials, vol. 3, no. 4, pp. 578-593, 1991.

[3] Y. Wang and G. Cao, "Synthesis and enhanced intercalation properties of nanostructured vanadium oxides," Chemistry of Materials, vol. 18, no. 12, pp. 2787-2804, 2006.

[4] V. Augustyn and B. Dunn, "Vanadium oxide aerogels: nanostructured materials for enhanced energy storage," Comptes Rendus Chimie, vol. 13, no. 1-2, pp. 130-141, 2010.
[5] C. O’Dwyer, V. Lavayen, D. A. Tanner et al., "Reduced surfactant uptake in three dimensional assemblies of $\mathrm{VO}_{x}$ nanotubes improves reversible $\mathrm{Li}^{+}$intercalation and charge capacity," Advanced Functional Materials, vol. 19, no. 11, pp. 1736-1745, 2009.

[6] D. McNulty, D. N. Buckley, and C. O’Dwyer, "Synthesis and electrochemical properties of vanadium oxide materials and structures as Li-ion battery positive electrodes," Journal of Power Sources, vol. 267, pp. 831-873, 2014.

[7] M. Osiak, H. Geaney, E. Armstrong, and C. O’Dwyer, "Structuring materials for lithium-ion batteries: advancements in nanomaterial structure, composition, and defined assembly on cell performance," Journal of Materials Chemistry A, vol. 2, no. 25, pp. 9433-9460, 2014.

[8] M. J. Armstrong, C. O’Dwyer, W. J. Macklin, and J. D. Holmes, "Evaluating the performance of nanostructured materials as lithium-ion battery electrodes," Nano Research, vol. 7, no. 1, pp. 1-62, 2014.

[9] T.-D. Nguyen, "From formation mechanisms to synthetic methods toward shape-controlled oxide nanoparticles," Nanoscale, vol. 5, no. 20, pp. 9455-9482, 2013.

[10] S. H. Ng, S. Y. Chew, J. Wang et al., "Synthesis and electrochemical properties of $\mathrm{V}_{2} \mathrm{O}_{5}$ nanostructures prepared via a precipitation process for lithium-ion battery cathodes," Journal of Power Sources, vol. 174, no. 2, pp. 1032-1035, 2007.

[11] H. Kaper, M.-G. Willinger, I. Djerdj, S. Gross, M. Antonietti, and B. M. Smarsly, "IL-assisted synthesis of $\mathrm{V}_{2} \mathrm{O}_{5}$ nanocomposites and $\mathrm{VO}_{2}$ nanosheets," Journal of Materials Chemistry, vol. 18, no. 47, pp. 5761-5769, 2008.

[12] L. Mao, C. Liu, and J. Li, "Template-free synthesis of $\mathrm{VO}_{x}$ hierarchical hollow spheres," Journal of Materials Chemistry, vol. 18, pp. 1640-1643, 2008. 
[13] N. Asim, S. Radiman, M. A. Yarmo, and M. S. B. Golriz, "Vanadium pentoxide: synthesis and characterization of nanorod and nanoparticle $\mathrm{V}_{2} \mathrm{O}_{5}$ using CTAB micelle solution," Microporous and Mesoporous Materials, vol. 120, no. 3, pp. 397-401, 2009.

[14] J. H. Kim, Y. C. Hong, and H. S. Uhm, "Synthesis of oxide nanoparticles via microwave plasma decomposition of initial materials," Surface and Coatings Technology, vol. 201, no. 9-11, pp. 5114-5120, 2007.

[15] C. V. Ramana, R. J. Smith, O. M. Hussain, C. C. Chusuei, and C. M. Julien, "Correlation between growth conditions, microstructure, and optical properties in pulsed-laser-deposited $\mathrm{V}_{2} \mathrm{O}_{5}$ thin films," Chemistry of Materials, vol. 17, no. 5, pp. 1213-1219, 2005.

[16] F. Krumeich, H.-J. Muhr, M. Niederberger, F. Bieri, B. Schnyder, and R. Nesper, "Morphology and topochemical reactions of novel vanadium oxide nanotubes," Journal of the American Chemical Society, vol. 121, no. 36, pp. 8324-8331, 1999.

[17] W. Avansi Jr., C. Ribeiro, E. R. Laite, and V. R. Mastelaro, "Vanadium pentoxide nanostructures: an effective control of morphology and crystal structure in hydrothermal conditions," Crystal Growth \& Design, vol. 9, no. 8, pp. 3626-3631, 2009.

[18] M. R. Parida, C. Vijayan, C. S. Rout, C. S. S. Sandeep, R. Philip, and P. C. Deshmukh, "Room temperature ferromagnetism and optical limiting in $\mathrm{V}_{2} \mathrm{O}_{5}$ nanoflowers synthesized by a novel method," The Journal of Physical Chemistry C, vol. 115, no. 1, pp. 112-117, 2011.

[19] Y. Zhou, Z. Qiu, M. Lü, A. Zhang, and Q. Ma, "Preparation and characterization of $\mathrm{V}_{2} \mathrm{O}_{5}$ macro-plates," Materials Letters, vol. 61, no. 19-20, pp. 4073-4075, 2007.

[20] H.-L. Fei, M. Liu, H.-J. Zhou, P.-C. Sun, D.-T. Ding, and T.-H. Chen, "Synthesis of $\mathrm{V}_{2} \mathrm{O}_{5}$ micro-architectures via in situ generation of single-crystalline nanoparticles," Solid State Sciences, vol. 11, no. 1, pp. 102-107, 2009.

[21] C. Díaz, M. L. Valenzuela, N. Yutronic, V. Villalobos, and G. Barrera, "Nanostructured VOx/VO $\left(\mathrm{PO}_{4}\right)_{n}$ using solid-state vanadium containing phosphazene precursors: a useful potential Bi-catalyst system," Journal of Cluster Science, vol. 22, no. 4, pp. 693-704, 2011.

[22] C. Díaz, M. L. Valenzuela, V. Lavayen, K. Mendoza, D. O. Peña, and C. O’Dwyer, "Nanostructured copper oxides and phosphates from a new solid-state route," Inorganica Chimica Acta, vol. 377, no. 1, pp. 5-13, 2011.

[23] K. Desai, K. Kit, J. Li, and S. Zivanovic, "Morphological and surface properties of electrospun chitosan nanofibers," Biomacromolecules, vol. 9, no. 3, pp. 1000-1006, 2008.

[24] Q. Li, E. T. Dunn, E. W. Grandmaison, and M. J. Goosen, "Applications and properties of chitosan," Journal of Bioactive and Compatible Polymers, vol. 7, pp. 370-397, 1992.

[25] I. Aranaz, M. Mengíbar, R. Harris et al., "Functional characterization of chitin and chitosan," Current Chemical Biology, vol. 3, no. 2, pp. 203-230, 2009.

[26] R. B. Hernandez, O. R. Yola, and A. L. R. Mercê, "Chemical equilibrium in the complexation of first transition series divalent cations $\mathrm{Cu}^{2+}, \mathrm{Mn}^{2+}$ and $\mathrm{Zn}^{2+}$ with chitosan," Journal of the Brazilian Chemical Society, vol. 18, no. 7, pp. 1388-1396, 2007.

[27] I. S. Lima and C. Airoldi, "A thermodynamic investigation on chitosan-divalent cation interactions," Thermochimica Acta, vol. 421, no. 1-2, pp. 133-139, 2004.

[28] E. Taboada, G. Cabrera, and G. Cardenas, "SEM-EDX studies of chitosan derivatives-metal adducts," Journal of the Chilean Chemical Society, vol. 48, no. 4, pp. 49-53, 2003.
[29] K. Ogawa, K. Oka, and T. Yui, "X-ray study of chitosantransition metal complexes," Chemistry of Materials, vol. 5, no. 5, pp. 726-728, 1993.

[30] S. Schlick, "Binding sites of copper ${ }_{2+}$ in chitin and chitosan. An electron spin resonance study," Macromolecules, vol. 19, no. 1, pp. 192-195, 1986.

[31] J. Brugnerotto, J. Lizardi, F. M. Goycoolea, W. Argüelles-Monal, J. Desbrières, and M. Rinaudo, "An infrared investigation in relation with chitin and chitosan characterization," Polymer, vol. 42, no. 8, pp. 3569-3580, 2001.

[32] H. Huang and X. Yang, "Synthesis of polysaccharide-stabilized gold and silver nanoparticles: a green method," Carbohydrate Research, vol. 339, no. 15, pp. 2627-2631, 2004.

[33] Y. Ding, X.-H. Xia, and C. Zhang, "Synthesis of metallic nanoparticles protected with $N, N, N$-trimethyl chitosan chloride via a relatively weak affinity," Nanotechnology, vol. 17, no. 16, pp. 4156-4162, 2006.

[34] M. Adlim, M. Abu Bakar, K. Y. Liew, and J. Ismail, "Synthesis of chitosan-stabilized platinum and palladium nanoparticles and their hydrogenation activity," Journal of Molecular Catalysis A: Chemical, vol. 212, no. 1-2, pp. 141-149, 2004.

[35] K. Okitsu, Y. Mizukoshi, T. A. Yamamoto, Y. Maeda, and Y. Nagata, "Sonochemical synthesis of gold nanoparticles on chitosan," Materials Letters, vol. 61, no. 16, pp. 3429-3431, 2007.

[36] K. H. Yang, Y. Liu, T. Hsu, and H. I. Tsai, "pH-insensitive fabrication of gold nanoparticles with high concentration by ultrasound-assisted electrochemical process via aid of chitosan," Materials Research Bulletin, vol. 45, pp. 63-68, 2010.

[37] I. Zhitomirsky and A. Hashambhoy, "Chitosan-mediated electrosynthesis of organic-inorganic nanocomposites," Journal of Materials Processing Technology, vol. 191, no. 1-3, pp. 68-72, 2007.

[38] H. Huang, Q. Yuan, and X. Yang, "Preparation and characterization of metal-chitosan nanocomposites," Colloids and Surfaces B: Biointerfaces, vol. 39, no. 1-2, pp. 31-37, 2004.

[39] Y.-C. Chang and D.-H. Chen, "Preparation and adsorption properties of monodisperse chitosan-bound $\mathrm{Fe}_{3} \mathrm{O}_{4}$ magnetic nanoparticles for removal of $\mathrm{Cu}(\mathrm{II})$ ions," Journal of Colloid and Interface Science, vol. 283, no. 2, pp. 446-451, 2005.

[40] L. Ding, C. Hao, Y. Xue, and H. Ju, "A bio-inspired support of gold nanopaticles-chitosan nanocomposites gel for immobilization and electrochemical study of K562 leukemia cells," Biomacromolecules, vol. 8, no. 4, pp. 1341-1346, 2007.

[41] Y. Du, X.-L. Luo, J.-J. Xu, and H.-Y. Chen, "A simple method to fabricate a chitosan-gold nanoparticles film and its application in glucose biosensor," Bioelectrochemistry, vol. 70, no. 2, pp. 342-347, 2007.

[42] E. Guibal, "Heterogeneous catalysis on chitosan-based materials: a review," Progress in Polymer Science, vol. 30, pp. 71-109, 2005.

[43] C. Díaz and M. L. Valenzuela, "Small molecule and high polymeric phosphazenes containing oxypyridine side groups and their organometallic derivatives: useful precursors for metal nanostructured materials," Macromolecules, vol. 39, no. 1, pp. 103-111, 2006.

[44] P. Guo, W. Guan, L. Liang, and P. Yao, "Self-assembly of $\mathrm{pH}$-sensitive random copolymers: poly(styrene-co-4vinylpyridine)," Journal of Colloid and Interface Science, vol. 323, no. 2, pp. 229-234, 2008.

[45] L. A. Belfiore, M. P. McCurdie, and E. Ueda, "Polymeric coordination complexes based on cobalt, nickel, and ruthenium 
that exhibit synergistic thermal properties," Macromolecules, vol. 26, no. 25, pp. 6908-6917, 1993.

[46] A. Haynes, P. M. Maitlis, R. Quyoum et al., "Structure and reactivity of polymer-supported carbonylation catalysts," Journal of the Chemical Society, Dalton Transactions, no. 12, pp. 2565-2572, 2002.

[47] C. V. Franco, M. Marques da Silva Paula, G. Goulart, L. F. C. P. de Lima, L. K. Noda, and N. S. Gonçalves, "Thermal analysis, Raman spectroscopy and scanning electron microscopy of new polymeric material containing in-chain ruthenium complex: poly-trans- $\left[\mathrm{RuCl}_{2}(\mathrm{vpy})_{4}\right]$-co-styrene and poly-trans$\left[\mathrm{RuCl}_{2}(\mathrm{vpy})_{4}\right]-4$ vinylpyridine-styrene," Materials Letters, vol. 60, no. 21-22, pp. 2549-2553, 2006.

[48] F. Wen, W. Zhang, G. Wei et al., "Synthesis of noble metal nanoparticles embedded in the shell layer of coreshell poly(styrene-co-4-vinylpyridine) micospheres and their application in catalysis," Chemistry of Materials, vol. 20, no. 6, pp. 2144-2150, 2008.

[49] S. Klingelfer, W. Heitz, A. Greiner, S. Oestreich, S. Forster, and M. Antoinietti, "Preparation of palladium colloids in block copolymer micelles and their use for the catalysis of the heck reaction," Journal of the American Chemical Society, vol. 119, no. 42, pp. 10116-10120, 1997.

[50] P. Zheng, X. Jiang, X. Zhang, W. Zhang, and L. Shi, "Formation of gold@polymer core-shell particles and gold particle clusters on a template of thermoresponsive and $\mathrm{pH}$-responsive coordination triblock copolymer," Langmuir, vol. 22, no. 22, pp. 93939396, 2006.

[51] Y. Xia, Y. Xiong, B. Lim, and S. E. Skrabalak, "Shape-controlled synthesis of metal nanocrystals: simple chemistry meets complex physics?" Angewandte Chemie-International Edition, vol. 48, no. 1, pp. 60-103, 2009.

[52] W. Niu, L. Zhang, and G. Xu, "Seed-mediated growth of noble metal nanocrystals: crystal growth and shape control," Nanoscale, vol. 5, no. 8, pp. 3172-3181, 2013.

[53] S. Mostafa, F. Behafarid, J. R. Croy et al., "Shape-dependent catalytic properties of Pt nanoparticles," Journal of the American Chemical Society, vol. 132, no. 44, pp. 15714-15719, 2010.

[54] J. Brugnerotto, J. Desbrières, L. Heux, K. Mazeau, and M. Rinaudo, "Wet-spinning and applications of functional fibers based on chitin and chitosan," Macromolecular Symposia, vol. 168, pp. 21-30, 2001.

[55] C. D. Valenzuela, G. A. Carriedo, M. L. Valenzuela, L. Zúñiga, and C. O'Dwyer, "Solid state pathways to complex shape evolution and tunable porosity during metallic crystal growth," Scientific Reports, vol. 3, article 2642, 2013.

[56] J. Tauc, R. Grigorovici, and A. Vancu, "Optical properties and electronic structure of amorphous germanium," Physica Status Solidi (B), vol. 15, pp. 627-637, 1966.

[57] M. M. Mohamed, W. A. Bayoumy, M. Khairy, and M. A. Mousa, "Synthesis and structural characterization of $\mathrm{TiO}_{2}$ and $\mathrm{V}_{2} \mathrm{O}_{5} / \mathrm{TiO}_{2}$ nanoparticles assembled by the anionic surfactant sodium dodecyl sulfate," Microporous and Mesoporous Materials, vol. 97, no. 1-3, pp. 66-77, 2006.

[58] G. Carja, Y. Kameshima, and K. Okada, "Nanoparticles of iron and vanadium oxides supported on iron substituted LDHs: synthesis, textural characterization and their catalytic behavior in ethylbenzene dehydrogenation," Microporous and Mesoporous Materials, vol. 115, no. 3, pp. 541-547, 2008.

[59] K. Melghit and K. Bouziane, "Low-temperature preparation and magnetic properties of V-doped $\mathrm{SnO}_{2}$ nanoparticles," Journal of the American Ceramic Society, vol. 90, no. 8, pp. 2420-2423, 2007.

[60] C. Díaz, M. L. Valenzuela, V. Lavayen, and C. O’Dwyer, "Layered graphitic carbon host formation during liquid-free solid state growth of metal pyrophosphates," Inorganic Chemistry, vol. 51, no. 11, pp. 6228-6236, 2012.

[61] C. Díaz and M. L. Valenzuela, "Metallic nanostructures using oligo and polyphosphazenes as template or stabilizer in solid state," in Encyclopedia of Nanoscience and Nanotechnology, H. S. Nalwa, Ed., vol. 16, pp. 239-256, American Scientific Publishers, 2010.

[62] C. O’Dwyer, G. Gannon, D. McNulty, D. N. Buckley, and D. Thompson, "Accommodating curvature in a highly ordered functionalized metal oxide nanofiber: synthesis, characterization, and multiscale modeling of layered nanosheets," Chemistry of Materials, vol. 24, no. 20, pp. 3981-3992, 2012.

[63] G. Gannon, C. O’Dwyer, J. A. Larsson, and D. Thompson, "Interdigitating organic bilayers direct the short interlayer spacing in hybrid organic-inorganic layered vanadium oxide nanostructures," The Journal of Physical Chemistry B, vol. 115, no. 49, pp. 14518-14525, 2011.

[64] F. Wang, V. N. Richard, S. P. Shieds, and W. E. Buhro, "Kinetics and mechanisms of aggregative nanocrystal growth," Chemistry of Materials, vol. 26, no. 1, pp. 5-21, 2014.

[65] C. Díaz, M. L. Valenzuela, L. Zúñiga, and C. O’Dwyer, "Organometallic derivatives of cyclotriphosphazene as precursors of nanostructured metallic materials: a new solid state method," Journal of Inorganic and Organometallic Polymers and Materials, vol. 19, no. 4, pp. 507-520, 2009.

[66] A. Bhattacharjee, A. Rooj, M. Roy, J. Kusz, and P. Gütlich, "Solventless synthesis of hematite nanoparticles using ferrocene," Journal of Materials Science, vol. 48, no. 7, pp. 2961-2968, 2013.

[67] M. R. J. Scherer, L. Li, P. M. S. Cunha, O. A. Scherman, and U. Steiner, "Enhanced electrochromism in gyroid-structured vanadium pentoxide," Advanced Materials, vol. 24, no. 9, pp. 1217-1221, 2012.

[68] C. W. Zou, X. D. Yan, J. Han, R. Q. Chen, and W. Gao, "Microstructures and optical properties of $\beta-\mathrm{V}_{2} \mathrm{O}_{5}$ nanorods prepared by magnetron sputtering," Journal of Physics D: Applied Physics, vol. 42, no. 14, pp. 145402-145406, 2009.

[69] Z. S. El Mandouh and M. S. Selim, "Physical properties of vanadium pentoxide sol gel films," Thin Solid Films, vol. 371, no. 1, pp. 259-263, 2000.

[70] A. Kumar, P. Singh, N. Kulkarni, and D. Kaur, "Structural and optical studies of nanocrystalline $\mathrm{V}_{2} \mathrm{O}_{5}$ thin films," Thin Solid Films, vol. 516, no. 6, pp. 912-918, 2008.

[71] M. Losurdo, D. Barreca, G. Bruno, and E. Tondello, "Spectroscopic ellipsometry investigation of $\mathrm{V}_{2} \mathrm{O}_{5}$ nanocrystalline thin films," Thin Solid Films, vol. 384, no. 1, pp. 58-64, 2001.

[72] A. A. Akl, "Effect of solution molarity on the characteristics of vanadium pentoxide thin film," Applied Surface Science, vol. 252, no. 24, pp. 8745-8750, 2006.

[73] S. Krishnakumar and C. S. Menon, "Optical and electrical properties of vanadium pentoxide thin films," Physica Status Solidi A, vol. 153, no. 2, pp. 439-444, 1996.

[74] L. Ottaviano, A. Pennisi, F. Simone, and A. M. Salvi, "RF sputtered electrochromic $\mathrm{V}_{2} \mathrm{O}_{5}$ films," Optical Materials, vol. 27, no. 2, pp. 307-313, 2004.

[75] S. A. Aly, S. A. Mahmoud, N. Z. El-Sayed, and M. A. Kaid, "Study on some optical properties of thermally evaporated $\mathrm{V}_{2} \mathrm{O}_{5}$ films," Vacuum, vol. 55, no. 2, pp. 159-163, 1999. 
[76] G. Wu, K. Du, C. Xia et al., "Optical absorption edge evolution of vanadium pentoxide films during lithium intercalation," Thin Solid Films, vol. 485, no. 1-2, pp. 284-289, 2005.

[77] M. Benmoussa, E. Ibnouelghazi, A. Bennouna, and E. L. Ameziane, "Structural, electrical and optical properties of sputtered vanadium pentoxide thin films," Thin Solid Films, vol. 265, no. 1-2, pp. 22-28, 1995.

[78] C. V. Ramana, R. J. Smith, O. M. Hussain, C. C. Chgusuel, and C. M. Julien, "Correlation between growth conditions, microstructure, and optical properties in pulsed-laser-deposited $\mathrm{V}_{2} \mathrm{O}_{5}$ thin films," Chemistry of Materials, vol. 17, no. 5, pp. 1213-1219, 2005.

[79] R. Abazari, S. Sanati, and L. A. Saghatforousch, "Nonaggregated divanadium pentoxide nanoparticles: a one-step facile synthesis. Morphological, structural, compositional, optical properties and photocatalytic activities," Chemical Engineering Journal, vol. 236, pp. 82-90, 2014.

[80] A. Faggio, V. Modafferi, G. Panzera, D. Alfieri, and S. Santangelo, "Micro-Raman and photoluminescence analysis of composite vanadium oxide/poly-vinyl acetate fibres synthesised by electro-spinning," Journal Raman Spectroscopy, vol. 43, no. 6, pp. 761-768, 2012.

[81] Ch. Niu, Ch. Han, X. Zhao et al., "Synthesis and optical property of size-tunable vanadium oxide nano-dandelions," Journal of Nanoscience Letters, vol. 3, pp. 27-30, 2013.

[82] Y. Wang, Q. Su, C. H. Chen et al., "Low temperature growth of vanadium pentoxide nanomaterials by chemical vapour deposition using $\mathrm{VO}(\mathrm{acac})_{2}$ as precursor," Journal of Physics D: Applied Physics, vol. 43, no. 18, pp. 185102-185107, 2010.

[83] M. Anpo, I. Tanahashi, and Y. Kubokawa, "Photoluminescence and photoreductlon of $\mathrm{V}_{2} \mathrm{O}_{5}$ supported on porous Vycor glass," Journal of Physical Chemistry, vol. 84, no. 25, pp. 3440-3443, 1980.

[84] H. Li, S. Zhang, and Q. Zhong, "Effect of nitrogen doping on oxygen vacancies of titanium dioxide supported vanadium pentoxide for ammonia-SCR reaction at low temperature," Journal of Colloid and Interface Science, vol. 402, pp. 190-195, 2013.

[85] H. García, J. M. López-Nieto, E. Palomares, and B. Solsona, "Photoluminescence of supported vanadia catalysts: linear correlation between the vanadyl emission wavelength and the isoelectric point of the oxide support," Catalysis Letters, vol. 69, no. 3-4, pp. 217-221, 2000.

[86] Z. Hamnabard, Z. Khalkhali, S. S. A. Qazvini, S. Baghshahi, and A. Maghsoudipour, "Preparation, heat treatment and photoluminescence properties of $\mathrm{V}$-doped $\mathrm{ZnOSiO}_{2} \mathrm{~B}_{2} \mathrm{O}_{3}$ glasses," Journal of Luminescence, vol. 132, no. 5, pp. 1126-1132, 2012.

[87] W. Avansi, L. J. Q. Maia, C. Ribeiro, E. R. Leite, and V. R. Mastelaro, "Local structure study of vanadium pentoxide 1Dnanostructures," Journal of Nanoparticle Research, vol. 13, no. 10, pp. 4937-4946, 2011.

[88] A. Venkatesan, N. K. Chandar, S. Arjunan, K. N. Marimuthu, R. M. Kumar, and R. Jayavel, "Structural, morphological and optical properties of highly monodispersed PEG capped $\mathrm{V}_{2} \mathrm{O}_{5}$ nanoparticles synthesized through a non-aqueous route," Materials Letters, vol. 91, pp. 228-231, 2013.

[89] B. Yan, L. Liao, Y. You et al., "Single-crystalline $\mathrm{V}_{2} \mathrm{O}_{5}$ ultralong nanoribbon waveguides," Advanced Materials, vol. 21, no. 23, pp. 2436-2440, 2009.

[90] Y. Wang and Z. Zhang, "Oxygen deficient $\mathrm{V}_{2} \mathrm{O}_{5}$ nanorods for gas sensing," Physica E: Low-Dimensional Systems and Nanostructures, vol. 43, no. 9, pp. 1726-1729, 2011.
[91] T. Puangpetch, S. Chavej, and T. Sreethawong, "Mesoporousassembled $\mathrm{V}_{2} \mathrm{O}_{5}$ nanosheet synthesized via a surfactantmodified sol-gel technique and its photocatalytic $\mathrm{H} 2$ production activity under visible light irradiation," Powder Technology, vol. 208, no. 1, pp. 37-41, 2011.

[92] H. Liu, Y. Gao, J. Zhou et al., "Growth of oriented vanadium pentaoxide nanostructures on transparent conducting substrates and their applications in photocatalysis," Journal of Solid State Chemistry, vol. 214, pp. 79-85, 2014.

[93] S. Beke, S. Giorgio, L. Korösi, L. Nánai, and W. Marine, "Structural and optical properties of pulsed laser deposited $\mathrm{V}_{2} \mathrm{O}_{5}$ thin films," Thin Solid Films, vol. 516, no. 15, pp. 46594664, 2008.

[94] R. M. Oksuzoglu, P. Bilgic, M. Yildirim, and O. Deniz, "Influence of post-annealing on electrical, structural and optical properties of vanadium oxide thin films," Optic \& Laser Technology, vol. 48, pp. 102-109, 2013. 

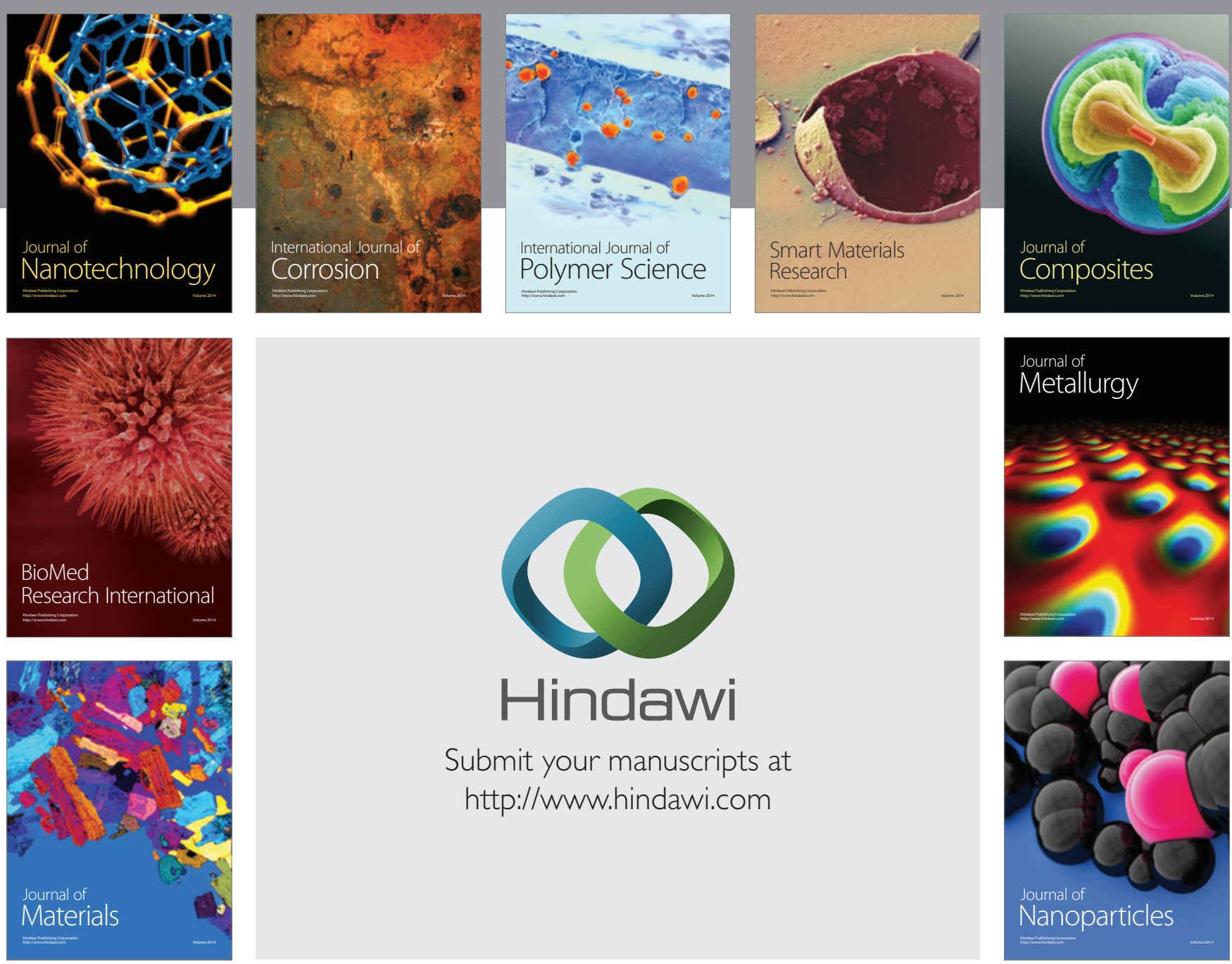

Submit your manuscripts at http://www.hindawi.com
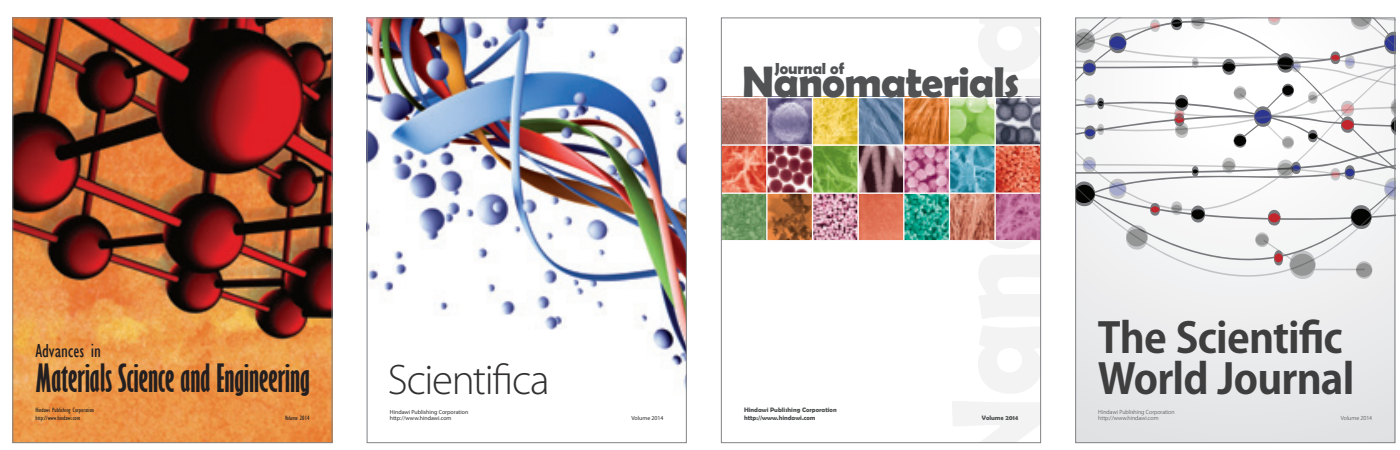

\section{The Scientific World Journal}
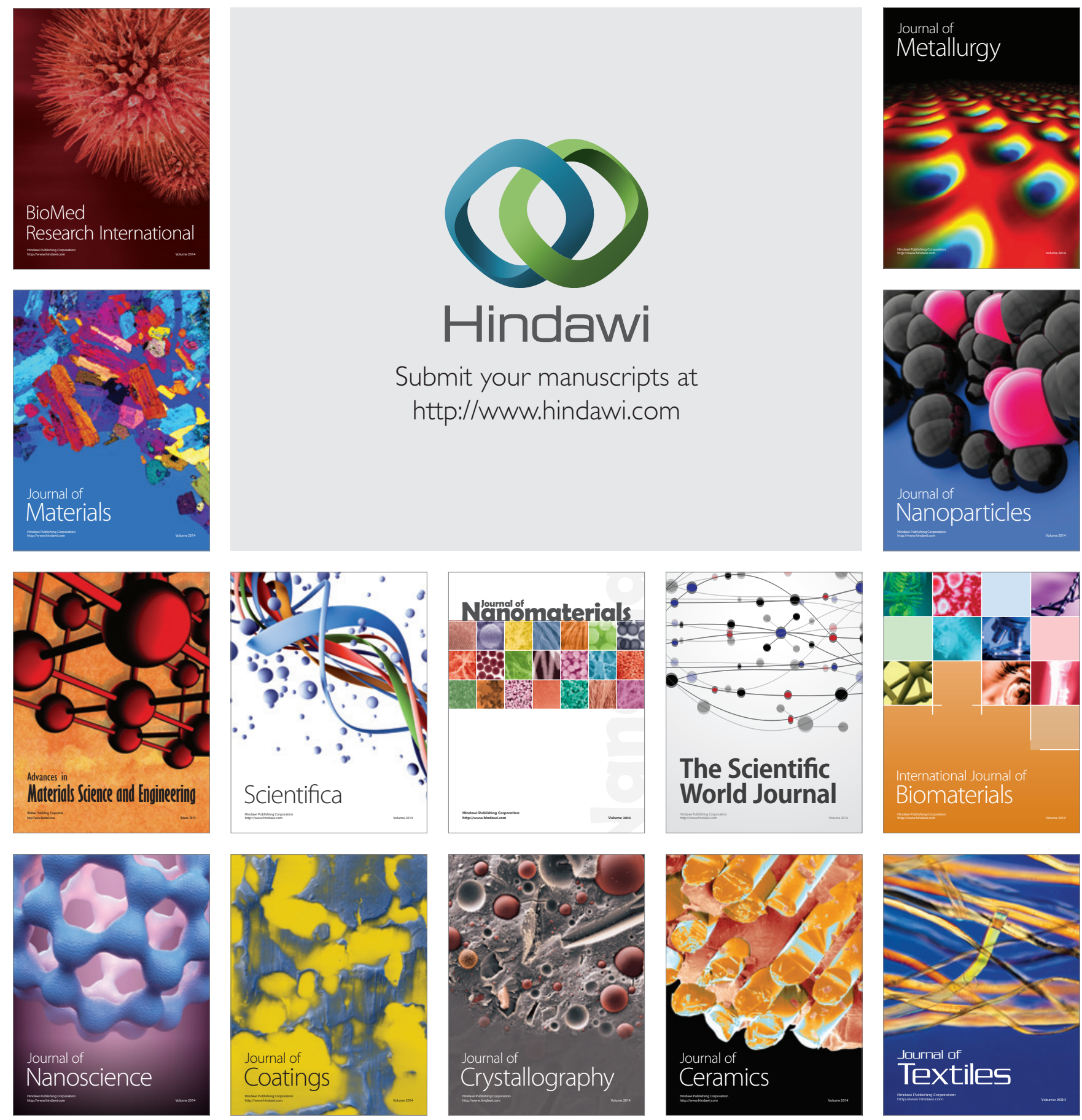